\title{
Beiträge zur Verwaltungsgeschichte Kandias im XIV. Jahrhundert.
}

Finleitung.

Im Herzen des östlichen Mittelmeeres, mit Cypern und Malta ungefähr auf gleicher Breite, liegt die Insel Kreta. Nach der Wiederaufrichtung des lateinischen Kaisertums in Byzanz gelangte Venedig dank der feinen Diplomatie des großen Enrico Dandolo ${ }^{1}$ ) im Jahre 1204 durch einen mit Bonifazius, dem Markgrafen von Montferrat, abgeschlossenen Vertrag um die Summe von 1000 Mark Silber und gegen Unterstützung bei der Erwerbung von Thessalonich in den Besitz von Kreta. ${ }^{2}$ ) Nach diesem Vertrag vom 12. August 1204, der sogenannten Refutatio Cretae $^{3}$ ), flatterte das Banner von S. Marco fast fünf Jahrhunderte hindurch auf diesem wundervollen Eilande, das durch seine dominierende transversale Lage zwischen drei Erdteilen zu allen Zeiten der Stützpunkt des Levantehandels, für Schiffahrt und Handel des Mittelmeeres überhaupt von hervorragender Bedeutung gewesen ist. ${ }^{4}$ )

Wo ehedem "unermeBlich viele Menschen" in 90 Städten wohnten, wie der Verfasser der Odyssee sich ausdrückt ${ }^{5}$ ), da fanden die Venezianer noch vier Städte vor, davon 3 an der Nordküste gelegen, nämlich Candida, welche der Insel den Namen gab, Rithymna, jetzt Rethimo

1) Fontes Rerum Austriacarum: Urkunden zur ältern Handels- und Staatsgeschichte der Republik Venedig von Tafel und Thomas, Wien 1857, II. Teil p. 512.

2) Wörtlich: vos ad presens michi dare debetis mille marchas argenti et t.untas possessiones a parte occidentis, quarum redditus sint decem milium yperperorum aureorum iuxta extimationem unius mei amici et alterius uestri annuatim. Ebenda. Vgl. Gerland, Gesch. des lat. Kaiserreiches I p. 26 (Beilage zum Jahresbericht d. Gymnas. zu Homburg v. d. H. 1903).

3) Tafel und Thomas II p. $512 \mathrm{ff}$. Die Vesträge bringt alle Flaminius Cornelius in seiner Creta sacra, Venedig 1755 , pars IV p. $222 \mathrm{ff}$.

4) Vgl. dazu Thomas: Die Kommission des Dogen Andreas Dandolo für die Insel Kreta v. J. 1350, Abh. d. I. Kl. d. k. bayer. Ak. d. Wiss. XIV. Bd. I. Abt. p. 167

5) 19. Gesang, Vers 174. 
genannt, Hierapytna und Kydonia, venezianisch Chanea. ${ }^{1}$ ) Diese Städte waren bevölkert mit einem Gemisch der verschiedensten Nationalitäten, die sich auf ihre besondern Sitten und Gewohnheiten steiften. Die förmliche Besitznahme der Insel erfolgte erst, als die Genuesen Angriffe wagten, sowohl an der Küste wie im Innern festen $\mathrm{FuB}$ faBten und die Inselbewohner gegen die neue Regierung aufstachelten. Allein unter Mitwirkung der venez. Patrioten von Konstantinopel gelang es, im Jahre 1210 die Genuesen dauernd aus den kretensischen Gewässern zu vertreiben. ${ }^{2}$ ) Freilich die einheimische Bevölkerung, die vor jedem eindringenden Feind in den schwer zugänglichen Gebirgstälern stets Schutz fand, war nicht durch die Waffen allein, sondern eher noch durch ein festes, militärisch streng durchgeführtes Verwaltungssystem zur Ruhe zu bringen. Der Doge Ziani, der Nachfolger Heinrich Dandolos ( $† 1205$ ), wählte dafür das altrömische System der Kolonisation. Er teilte die fruchtbaren Küstenstriche Kandias in Lehen auf, die an Edle und gewöhnliche Bürger der Republik, an Ritter und FuBgänger, gegen Verpflichtung zum Lehensdienst kostenlos übertragen werden sollten. ${ }^{3}$ )

Der Grundbau der Lehensverteilung ergibt sich aus den Staatsurkunden, die noch vollständig erhalten und im Urkundenbuch von Tafel und Thomas (II p. $129 \mathrm{ff}$.) zusammengestellt worden sind. Im Jahr 1211 wurden ein erstes Mal 132 Ritterlehen - cavalleriae und 48 Dienstlehen - sergentariae - abgeteilt. Später ging der anfangs streng beobachtete Unterschied der beiden Arten von Lehensgütern dahin, und alle hießen nur noch Ritterlehen. ${ }^{4}$ ) Vorbehalten waren die Besitzungen der Kirchen und Klöster und der Küstenstrich von Candida, den der Staat für sich beanspruchte, auch etwaige Silbergruben oder goldführende Gewässer. Das geistliche Gebiet und die Staatsgüter wurden in je 25 Lehen eingeteilt und zumeist in Pacht gegeben. Im Verlauf des 13. Jahrhunderts wurden noch 35 Lehen an einheimische, treu zu Venedig haltende Archontengeschlechter verteilt, so daß die Gesamtzahl der kandiotischen Lehen am Ende des Jahrhunderts sich auf mehrere Hundert belaufen mochte. ${ }^{5}$ )

Der Besitzer konnte mit seinem Lehen frei schalten und walten,

1) Dr. Fabricius, Die Insel Kreta, in Hettners Geogr. Zeitschrift, Leipzig 1897, p. 378.

2) G. Gerola, La dominazione genovese in Creta, p. 17 (Rovereto 1902).

3) Tafel und Thomas II p. 129: ut semper ad arma parati iureiurando tenerentur insulam Cretae custodire et defendere contra quoscumque pro solo Veneto dominio.

4) Zinkeisen, Geschichte de, osmanischen Reiches IV p. 634.

5) Ebencla 636 . 
es durfte verschenkt, vertauscht oder verkauft werden, aber nur an Venezianer und mit Einwilligung der herzoglichen Regierung. $\left.{ }^{1}\right)$ Die Handelsfreiheit erlitt nur die Einschränkung, daß die Ausfuhr von Lebensmitteln der herzoglichen Ermächtigung bedurfte.

In Jahre 1211 ging die erste Kolonistenexpedition, in sechs nach den verschiedenen Sestieri Venedigs benannte Fühnlein eingeteilt und aus 132 Rittern und 48 Knappen bestehend, unter Segel. ${ }^{2}$ ) Indem diese lateinischen Ritter Besitz ergriffen von den ihnen vom Herzog und seinen Räten bezeichneten Gütern und Weiden, traten sie in das Erbe der edlen einheimischen Geschlechter ein, die, den übrigen Einheimischen gleichgestellt, grollend den Boden behauten und nur mit dem gezückten Schwert in steter Furcht gehalten werden komnten. Unerträglich gestaltete sich das Verhältnis des neuen Herrschers zum Vasallen infolge der religiösen Gegensätze. Griechische und lateinische Orthodoxie, diese von der venezianischen Regierung begünstigt, jene gesetzmäBig unterdrückt und von der herrschenden Geistlichkeit naturgemäB gehaBt, muBten sich gegenseitig abstoßen. ${ }^{3}$ )

Durch das ganze 13. Jahrhundert bis in die Mitte des 14. hinein zog sich eine fast ununterbrochene Kette von Aufständen der Einheimischen gegen das venezianische Regiment. $\left.{ }^{4}\right)$

Da die Mehrzahl der Ritter gleich in den ersten Kämpfen umgekommen war, entschlob sich Venedig im Jahre 1222, abermals eine Abteilung Kolonisten unter denselben Bedingungen wie 1211 nach Kandia zu entsenden, welche zu den 200 schon bestehenden Lehen 60 neue besetzen sollten. ${ }^{5}$ ) An dieser zweiten Kolonisation waren auch griechische Geschlechter beteiligt, welche den Aufstand vom Jahre 1217 inszeniert hatten. Trotz dieser versöhnenden Großmut der Venezianer brachen die Kämpfe im Jahre 1230 von neuem los.

Im Jahre 1252 erfolgte ein weiterer Nachschub von Kolonisten, die das fast gänzlich zerstörte Chanea wieder aufbauen und 90 Ritterlehen errichten sollten. Daron beanspruchte der Staat 15 Lehen zu-

1) „Unter der Herrschaft der Venezianer, nachdem die Oberherrschaft der Republik geraume Zeit befestigt war, betrug die Berölkerung 271489 Köpfe in 996 Dörfern und einigen Städten." So berichtet L. Bürchner in einem Aufsatze üler "die Berölkerungszahl der Insel Kreta" in der Beilage znr Münchner Allg. Zeitung, $1903 \mathrm{Nr}$. 10. Im Jahre 1881 zïhlte man gleichviel, nämlich 279195 , in Jahre 1900 aber 301273 Menschen. Ebenda.

2) Tafel und Thomas II p. 136.

3) Vgl. Thomas, Kommission des Dogen A. Dandolo, a. a. O. Bil. XIV p. 171.

4) Vgl. Laur. de Monacis p. $15 \mathrm{fft}$, Creta sacra des Fianinius Comeliu. IV Ventiis 1755) und Tafel n. Thomas II p. 136 fl.

5: Tafel und Thomas II p. $234 \mathrm{ti}$. 
handen der herzoglichen Regierung. ${ }^{1}$ ) Im Jahre 1237 war eine Neuanordnung und Ergänzung der alten Kataster für sämtliche Besitzungen in Kandia erfolgt ${ }^{2}$ ), so daB die neuen Kolonisten im großen und ganzen geordnete Verhältnisse antreffen mochten.

Im Jahre 1304 wurde von Venedig aus gestattet, 3 oder 6 FuBgängerlehen zusammenzuziehen, wofür aber die Waffenpflicht zu Pferde bestehen sollte. ${ }^{3}$ ) Eine Petition im Jahre 1349 hatte zur Folge, daB die Vereinigung von Ritter- und FuBgängerlehen dem Ermessen des Herzogs anheimgestellt wurde. ${ }^{4}$ )

Die Aufstände der Brüder Georg und Theodor Cortazzi 1271 und des Alexios Kalergis 1282, die sich auf Jahre hinauszogen, weil die venezianische Übermacht im zerrissenen und zerklüfteten Innern des Gebirges sich nicht entfalten konnte, ließen in Venedig die Überzeugung aufkommen, daß Kandia erst dann zum gesicherten Besitz Venedigs erhoben werde, wenn die einheimischen Archontengeschlechter fest zur Mutterstadt hielten. Offene Begünstigungen bewirkten, daB einige Geschlechter sich an Venedig ketteten, wie z. B. die Familie des Alexios Kalergis $^{5}$ ), der, in den Adelstand erhoben, bis zur Mitte des 14. Jahrhunderts der Lagunenstadt kräftigen Beistand leistete.

Die tiefer liegenden Ursachen des Übels ließen sich aber auch auf diesem Wege nicht heben. Es liegt wohl in den Gesetzeserlassen Venedigs und vielleicht nicht weniger in der Art ihrer Ausführung, wenn eine Annäherung der Einheimischen und der Kolonisten, die sich dem Mutterlande entfremdet fühlten, an Venedig unmöglich erschien.

Um dies verstehen zu können, müssen wir uns einen Einblick in die venezianische Verwaltung Kandias im 14. Jahrhundert gestatten, soweit die vorhandenen Materialien reichen.

Dis vornehmste und ausgiebigste Quelle zur Geschichte der innern Einrichtung und Verwaltung der Insel Kreta unter venezianischer Herrschaft bietet das Archivio del duca di Candia im Kgl. Archiv dei Frari in Venedig. ${ }^{6}$ ) Der dortige Vorsteher, Herr Prof. Predelli, hat dasselbe geordnet und dessen Benutzung ermöglicht, und Dr. Gerland in Homburg v. d. H. hat es einer genauen Durchsicht unterzogen und die Resultate in der oben zitierten Schrift niedergelegt.

1) Tafel und Thomas II p. $470 \mathrm{ff}$.

2) E. Gerland, Das Archiv des Herzogs ron Kandia, StraBburg 1899, p. 76.

3) Ebenda p. 44, erwähnt in Creta sacra IV p. 306.

4) Gerland, Archiv p. 56 .

5) Die Pax Alexii C'alergi abgedruckt in Tafel und Thomas III p. $376 \mathrm{ff}$. und in Gerland, Archiv p. $121 \mathrm{ff}$., sowie von Xanthudidis in der Athena Bd. XIV.

6) Die nähere Beschreibung desselben bei Gerland, Archir p. $9 \mathrm{ff}$. 
Wir besitzen wenige Darstellungen über die Geschichte Kretas und darunter keine auch nur annähernd zureichende; ist doch der Urquell jeglicher Forschung auf diesem Gebiet, das Herzogliche Archiv, bis dahin nur ausnahmsweise benützt worden.

Von den älteren Forschern stellen wir in erste Linie den venezianischen Chronisten Laurentius de Monacis, Sekretär in Kreta von 1388-1429. Sein Werk, das im IX. und X. Buche die kretensische Geschichte bis zum Jahre 1367 enthält, ist von Flaminius Cornelius im Jahre 1758 in Venedig herausgegeben worden. Ihm steht ebenbürtig zur Seite Fl. Cornelius selbst, der als Senator der Republik in seiner Creta sacra ein vortreffliches, das Herzogliche Archiv reich benützendes Werk herausgegeben hat.

Unter den neuen Forschern steht Zinkeisen mit seiner Geschichte Kretas, die im 4. Bande seiner Geschichte des osmanischen Reiches niedergelegt ist, einzig da. Da aber Zinkeisen das Archiv des Herzogs von Kandia nie gesehen hat, dürfte seine Darstellung für die ältere Geschichte Kandias schwerlich ins Gewicht fallen. Eine neuere Darstellung der Geschichte Kretas in der ersten venetianischen Periode gibt es also nicht. Derjenige, der sich diese Aufgabe gestellt, ist gestorben, bevor der I. Band seiner Urkundensammlung herauskam. Es ist Hippolyte Noiret ${ }^{1}$ ), der mit seinen Auszügen aus den Registerbänden der Senato Misti und Senato Mar wertvolle Bausteine für eine Geschichte Kandias im 15. Jahrhundert besonders nach der handelspolitischen Richtung hin geliefert hat.

Aus den dickleibigen Bänden des Archivs haben wir für unsere Beiträge den auch nach Gerlands Ansicht ${ }^{2}$ ) wichtigsten bearbeitet. Für die Administration Kandias im 14. Jahrhundert geben uns die Quaterni bannorum, deren erster von uns benützter Band die Jahre 1314-74 umfaßt, das wertrollste Material.

\section{Die Behörden von Kandia.}

Die Insel Kandia wurde während der venezianischen Herrschaft in folgende nach den Hauptstädten benamnte vier Territorien oder Distrikte eingeteilt: Candida mit dem Regierungssitz, Rethimo westlich davon, Chanea in westlichen und Sithia im östlichen Zipfel der Insel. $\left.{ }^{3}\right)$

1) Documents inédits pour servir à l'histoire de la domination vénitienne en Crète de 1380-1485, Paris 1892.

2) Archiv p. 18.

3) Vgl. bei Noiret die Carte de l'île de Crète sons la domination rénitienne, die aber sehr unvollständig ist. 
Der gesamte Regierungs- und Verwaltungsorganismus Kandias ist im großen und ganzen nur das verkleinerte Spiegelbild der Regierung von S. Marco. E. Gerland teilt in seinem „Archiv des Herzogs von Kandia", gestützt auf die Publikationen von Thomas und die von ihm selbst veröffentlichten Kapitulare für die kandiotischen Beamten vom Jahre 1289/90 p. $91 \mathrm{ff}$, die Beamtenschaft der Insel in zwei Klassen ein, in eine erste, höhere, die sich aus venezianischen Edlen zusammensetzte, direkt der Zentralregierung von Venedig unterstand und von dort ihre Vorschriften empfing, und in eine zweite, niedere, die unmittelbar rom Herzog und seinen Beratern eingesetzt und geleitet wurde und sich meist aus Einheimischen rekrutierte. ${ }^{1}$ ) Diese Einteilung soll hier beibehalten werden.

Der ersten Kategorie gehörten an: der Herzog (ducha), die zwei Räte (consiliarii), der Kapitän von Kreta, doch erst vom 14. Jahrhundert an, die Kämmerer (camerarii) und die Rektoren (rectores) der vier Distrikte, wenn wir Candida mitzählen. ${ }^{2}$ )

Das Kapitulare für den ducha scheint nicht mehr vorhanden zu sein. Als Gouverneur von Kandia hatte er das Wohl der Insel im weitesten Sinne ins Auge zu fassen und den Gang der Staatsgeschäfte, besonders auf dem Gebiete der Justiz und der Zollbestimmungen, zu überwachen. Aus der Kommission des consiliarius Stephanus Bragadino $^{3}$ ) geht hervor, daB man den Herzögen bei ihrer Abreise von Venedig auch gelegentlich Kommissionen mitgab. Die Amtsdauer des Herzogs war auf zwei Jahre eingeschränkt, womit usurpatorische Gelüste von vornherein gedämpft werden sollten, hauptsächlich aber, um möglichst viele venezianische Edle, reiche und arme, in diese einträglichen Stellen zu bringen. Der Herzog, der seine Frau nicht mitnehmen durfte, und die zwei Räte waren auf Kosten des Staates logiert, der bei der Neuwahl mitunter ganz ordentliche Sümmchen für Reparaturen an ihren Palästen votierte. ${ }^{4}$ ) Der Herzog bezog seit dem Jahre 1275 ein jährliches Fixum von 1000 Dukaten $(10-12000 \text { Fr. })^{5}$ ), vom Jahre 1426 an ein Drittel mehr. ${ }^{6}$ ) Dann wurden gewöhnlich alle fünf

1) Im Jahre 1392 wird bestimmt, daB die Regierung von Candida Burgvogteien und andere beliebige Ämter bei hoher $B u B e$ nur an Personen vergeben dürfe, die wenigstens seit fünf Jahren auf der Insel ansässig seien. Noiret p. 50.

2) Vgl. unten S. 443.

3) Thomas, Abh. d. I. Kl. d. k. Ak. d. Wiss. Bd. XIV p. $165 \mathrm{ff}$.

4) Noiret p. 18, 83 etc.

5) Thomas, Älteste Verordnungen, a. a. O. p. 113 Nr. 19. Vorher waren es nur 900 Dukaten.

6) Ut reperiri possint nobiles sufficientes et apti, qui illuc accedere uellint et non expendant de suo. Noiret p. 314 . 
Jahre $^{1}$ ) zwei Provisoren oder Sindici, von einem Notar und der Dienerschaft begleitet, mit weitgehender Vollmacht ${ }^{2}$ ) nach Kreta gesandt, wo sie längere Zeit verblieben, um die Rechnung zu passieren, das Gerichtswesen zu prüfen und die Funktionen der Regierung zu überschauen. Schuldige wurden von ihnen nach Venedig zitiert, schwer Beschuldigte unter polizeilicher Bewachung. An jedem Orte war es ihnen gestattet, 12 Einwohner, Griechen und Lateiner, ins Verhör zu nehmen und Klagen über die Verwaltung anzuhören mit dem Vermerk, daB unberechtigte Anschuldigungen schwer geahndet würden. ${ }^{3}$ ) In Kriegszeiten sandte der Senat von Venedig einen außerordentlichen Provisor mit diktatorischer Gewalt für ein Jahr nach Kreta. ${ }^{4}$ ) Der Herzog legte nach Ablauf seiner Amtsdauer in Venedig einen Verwaltungsbericht ab. ${ }^{5}$ )

Dem ducha standen zwei consiliarii zur Seite, über deren Befugnisse sich einige wichtige Bestimmungen bei Thomas (Bd. XIII älteste Verordnungen p. 108-116) und in der Kommission des Dogen Andreas Dandolo (Bd. XIV p. $183 \mathrm{ff}$.) aussprechen.

Der Herzog und die zwei consiliarii bildeten das Regierungskollegium, in dem nach Stimmenmehrheit entschieden wurde. Im Jahre 1438 wurde verfügt, dab bei Meinungsverschiedenheiten im Kollegium der Kapitän von Kreta beizuziehen sei. ${ }^{6}$ )

Der zweithöchste im Rang war der Kapitän von Kreta, Kommandant der Truppen. Wie der Herzog war auch er vom großen Rat in Venedig auf zwei Jahre gewählt und erhielt im Moment seiner Abreise einen Kredit von 350-400 Dukaten für die Ausrüstung seiner Kompagnien $^{7}$ ), die mit jedem neuen Kapitän wechselten ${ }^{8}$ ) und deren

1) Noiret p. 525 erwähnt einen Fall aus dem Jahre 1473, wo die Sindici erst uach Ablauf von 8 Jahren abgesandt wurden.

2) $\mathrm{Vgl}$. bei Noiret. Introd. p. $X$, dann die Instruktionen aus den Jahren 1396,1413 und 1438 p. $76 \mathrm{ff}$., $216 \mathrm{ff}$. und $378 \mathrm{ff}$.

3) Um diese Stellen wird man sich in Venedig nicht gerissen haben. Noiret führt an (p. 78), daB im Jahre 1396 ihrer 5 die Wahl ausgeschlagen haben, dafür aber mit 100 Dukaten gebüBt worden sind.

4) Nach Zinkeisen Bd. 4 p. 610 wäre ein solcher zum erstenmal im Jahre 1347 eruannt worden. Dann z. B. auch im Jahre 1364 nach Ausbruch der groBen Revolution; vgl. meine Arbeit in der B. Z. XII (1903) p. 86.

5) Im Jahre 1419 wird bestimmt: Wenn der Herzog auf der Insel einen Umritt unternimmt, darf seine Begleitung 40 Berittene, die tägliche, aus der Gemeindekasse geschöpfte Ausgabe XV Hyperpern umfassen, die Unkosten für Pferde und Maultiere nicht mitgerechnet. Für die consiliarii je die Hälfte. Noiret p. 268.

Im Jahre 1429 wird es untersagt, den Herzögen von Kreta bei ihrem Erscheinen oder bei ihrer Abreise den Weg mit Mvrten, Getreide, Salz 1. a. m. zu bestreuen. Noiret p. $335 . \quad 6)$ Noiret p. 378.

7) Zwei zu FuB und eine zu Pferd, Noiret p. 291 . 8) Noiret Introd. p. VII. Byzant. Zeitschrift XIII 3 u. 4. 
Stärke in Jahre $1440^{1}$ ) zur Verminderung der Kosten reduziert wurde. Die Polizeiwache Kretas besorgten unter seinem Oberbefehl $11 \mathrm{Kom}-$ pagnien $^{2}$ ) FuBtruppen, deren ursprünglicher Bestand von 19 Mann zuerst auf 22 erhöht, im Jahre 1443 auf 16 Mann herabgemindert wurde. Dazu kamen noch 4 Schwadronen Kavallerie zu 19, dann auch zu 16 Mann. $^{3}$ ) Mit dem damit ersparten Gelde sollten die Reparaturen im Arsenal ausgeführt werden.) Der capitaneus Crete vertrat bei $\mathrm{Ab}$ wesenheit den Herzog, war, wie wir oben gesehen, stimmberechtigter Beisitzer im Kollegium, bezog ebenfalls ein Gehalt von 1000, vom Jahre 1426 an von 1350 Dukaten. Ihm unterstanden direkt die connetabili oder Kompagniekapitäne, welche die allwöchentlichen Übungen leiteten, sowie die domini de nocte. Laut Kommission war er verpflichtet, einmal während seiner Amtszeit die Revue der Feudati abzunehmen. ${ }^{5}$ )

Vorschriften regelten die Bestallung des Herzogs und des Kapitäns, die Zahl ihrer Diener, sogar das Tragen der Trauerkleider. ${ }^{6}$ )

Die camerarii, ursprünglich zwei, von 1270 an drei, bildeten die oberste Finanzbehörde der Insel..$\left.^{7}\right)^{\circ}$

Obwohl sie ihre Vorschriften von der Zentralregierung von Venedig empfingen, waren sie doch gewissermaBen dem Regierungskollegium unterstellt, hatten auf dessen Wunsch Rechnung abzulegen, konnten aber bei Stimmengleichheit oder Abwesenheit eines Regierungsmitgliedes zu Rate gezogen werden. Der AbschluB von Geldgeschäften war den camerarii und den Steuereinnehmern außerhalb der Kanzlei aufs schärfste untersagt. ${ }^{8}$ ) Ihre Unterbeamten, die ihnen von Zeit zu Zeit Kasse und Protokoll vorlegen mußten, waren die scribae, cancellarii, misseti ${ }^{9}$ ), die zuerst der große Rat in Venedig, später die Regierung von Kandia wählte. ${ }^{10}$ )

Dieselbe Rangabstufung findet sich in den Hauptorten der Di strikte, wenigstens weist es Thomas ${ }^{11}$ ) nach für Rethimo und Chanea, wo die camerarii zugleich als consiliarii des Rektors amteten. $\mathrm{Ob}$ sie als selbständige Finanzbehörde nur der Regierung von Candida oder aber den camerarii Candide Rechnung ablegen muBten, läßt sich nicht feststellen.

1) Noiret p. 395 und 396.

2) Uber Zusammensetzung der Kompagnien vgl. Noiret p. 400.

3) Der Antrag auf Reduzierung der Truppenstärke wurde schon im Jahre 1440 gestellt, aber verworfen. Noiret p. 396.
4) Noiret p. 403.
5) Noiret p. 249.
6) Noiret p. 319 .
7) Thomas, Älteste Verordnungen Bd. XIV p. $115 \mathrm{Nr} .1$ und p. 116 Nr. 4.
8) Noiret p. 134.
9) Vgl. Noiret p. 251.
10) Noiret Introd. p. VIII.
11) Bd. XIII p. 116 Nr. 3. 
Ein Kapitulare für die Rektoren fehlt. Laut den Bestimmungen der Kommission für Stephan Bragadino fungierten je ein Rektor in Chanea, Rethimo und Sithia, und da sie die Regierung vertraten, begreifen wir, daB in Caudida ein solches Amt kaum bestand. Nachgewiesen ist der rector Candide nur, um interimistisch die Regierungsgeschäfte zu leiten, wenn der alte Herzog abgereist und der neue noch nicht angelangt war. ${ }^{1}$ ) Wohl aber kam es vor, dab die consiliarii zuzeiten oder vorübergehend auch zugleich als Rektoren amtierten. So steht bei Thomas in einem BeschluB des Jahres $1273^{2}$ ), daB ein consiliarius gleichzeitig rector von Rethimo sein solle.

Den Rektoren war laut Bestimmungen der Jahre 1260-1278 ${ }^{3}$ ) der Privathandel, die Annahme von Geschenken und Geldanleihen bis ein halbes Jahr über ihre Abberufung untersagt. Vom Jahre 1401 an muBten sie Verwaltungsberichte abliefern. ${ }^{4}$ ) Als der Rektor von Rethimo die Beamtenstellen nur mit seinen Freunden besetzte, wurde im Jahre 1415 von Venedig aus angeordnet, daB diese Posten mit AusschluB der Wiederwählbarkeit des Inhabers nur für 6 Monate, die Advokatenstellen für ein Jahr zu vergeben seien. ${ }^{5}$ )

Den erwachsenen Söhnen aller höheren Beamten sollte ein längerer Aufenthalt auf der Insel untersagt werden. Der Antrag wurde aber abgewiesen. $^{6}$ )

Bevor wir auf die zweite Beamtenkategorie eingehen, müssen wir die parlamentarischen Einrichtungen erwähnen, die wiederum Venedig nachgebildet sind. Die Vereinigung sämtlicher venezianischer Adeligen bildete den großen Rat (consilium maius), dem sie auf Lebenszeit angehörten. Ein engerer AusschuB, die Rogati oder Pregadi (in Venedig Senat) geheißen, der sich alle Jahre einmal konstituierte, führte mit der Signoria die Geschäfte. Zur wichtigsten Versammlung schwang sich im 14. Jahrhundert das consilium feudatorum auf, das in der Kevolution vom Jahre 1363 den Abfall der Kolonie bewirkte und für

1) Gerland, Archiv p. 89. Vg]. auch im Text p. 458 N. 83, wo der rector et eius consilium erwähnt wird.

2) Bd. XIII p. 111.

3) Thomas, Älteste Verordnungen, a. a. O. XIII p. 133-135.

4) Noiret p. 115. Im Jahre 1356 wurde verfügt, daB alle Unterbeamten des Rektors von Chanea, ausgenommen die Schreiber und Getreideabschätzer, aus dem Rate von Venedig oder von Chanea zu wählen seien. Als man Bauern et aliis vilibus personis die Ämter öfnete, wurde im Jahre 1420 wieder auf obige Bestimmung aufmerksam gemacht. Noiret p. 270.

5) Noiret p. 234 .

6) Noiret p. 76; vgl. auch Thomas, Älteste Verordnungen, a. a. O. Bd. XIII p. 109 Nr. 2. 
einige Zeit eine anarchistisch gefärbte Autonomie herstellte. Eigene camerarii besorgten die leitenden Geschäfte. ${ }^{1}$ )

Damit gehen wir zur zweiten Beamtenklasse über, welche, der ersten unterstellt, von ihr die Vorschriften bezog. Aus dem Kapitular der iudices ${ }^{2}$ ) ergeben sich zwei Richterkollegien, jedes zu drei Stellen, die curia iudicum proprii und die curia petitionum. In den Kollegien amtierten drei Richter, die sich gegenseitig vertraten. Sie waren verpflichtet, morgens $9 \mathrm{Uhr}$ vor dem Ausläuten der Markusglocken sich in ihren Bureaus einzufinden, die Geschäfte vorschriftsgemäß und rechtzeitig abzuwickeln, damit die Klienten vom Lande nicht zu warten brauchten und dadurch Schaden erlitten. Die Staatsanwälte mußten zu dem Behufe die Kanzleien inspizieren, die säumigen Beamten notieren und nach dem Grade der Verfehlung vom Gehalt abstreichen. So haben die Venezianer auf einem der wichtigsten Verwaltungszweige moderne Strenge walten lassen. Für die ganze Insel galt das venetianische Statut, nur für die Griechen hatte man griechisches Recht.

Für die Juden und Griechen bestand zur Rechtsprechung in Zivilsachen die curia prosoporum. Das Urteil der presoppi oder prosopi richtete sich nach venezianischem Statut, in Streitigkeiten wegen Mitgift nach griechischem. ${ }^{3}$ )

Zwei Polizeiorgane, die iustitiarii und die domini de nocte, sorgten für Ruhe und Ordnung innerhalb der Stadt und der Burg. Die iustitiarii, deren Kapitular uns unbekannt ist, waren die Aufsichtsbehörde auf dem Markt und besorgten die Inspektion der Fleischstände, der Früchte, Maße und Gewichte. ${ }^{4}$ ) Die domini de nocte wachten über die persönliche Sicherheit und waren mit einem Teil der Kriminaljustiz über Fälle, die sich zur Nachtzeit zutrugen, und mit der Hilfeleistung bei Feuersbrünsten betraut. ${ }^{5}$ ) Jedem der drei domini unterstanden neun wohlbewaffnete Unterbeamte (custodes), die nachts in stärkeren Abteilungen patroullierten. Zur Zeit, als die Stadt Candida in vier Quartiere abgeteilt war, gab es vier domini de nocte, vom Jahre 1392 an nur noch drei. ${ }^{6}$ )

Die älteste Polizeibehörde mit ursprünglich nur militärischen und richterlichen Funktionen sind die capitanei. ${ }^{7}$ ) Bei der ersten Besiedelung Kretas im Jahre 1212 wurde an die Spitze eines jeden Sestiere

1) Gerland, Archiv p. 49.

2) Gerland, Archiv p. $93 \mathrm{ff}$.

3) Gerland, Archiv p. 98.

4) Vgl. die Proclami zum Kapitel „Berufsklassen“ p. $469 \mathrm{ff}$.

5) Vgl. das Kapitulare bei Gerland, Archiv p. $95 \mathrm{ff}$. In Venedig hieBen sie gleich: signori di notte.

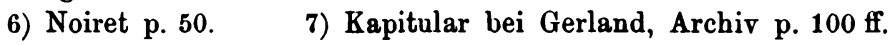


ein capitaneus gestellt. ${ }^{1}$ ) Ihm unterstanden sämtliche Ritter seines Bezirkes, an deren Spitze er sich zum Kampfe gegen die Rebellen stellte. Als Richter darf er in seinem Kapitanat Strafen verhängen bis zu 10 Hyperpern, und Streitigkeiten unter den Feudati schlichten, wobei ihm ein Strafma $B$ bis zu 25 Hyperpern zustand. Seine polizeilichen Pflichten umfaBten das Aufsuchen von Räubern, Gebannten und Mördern in seinem Distrikte und Auslieferung derselben nach Candida, das Aussenden von Spionen zur Aufspürung Verdächtiger und gelegentliche Streif- und Plünderungszüge gegen Aufständische.

Den Kapitänen eigenmächtig zur Seite und mit derselben Strafkompetenz ausgerüstet, standen zur Bewachung der Kastelle und deren Bemannung die Kastellane. ${ }^{2}$ ) Neben der stehenden Besatzung waren die umwohnenden Lehensleute zum Dienst im Kastell verpflichtet, das gleichsam einen eximierten Bezirk innerhalb des Sestiere vorstellte. ${ }^{3}$ ) Die Kastelle dienten als Stützpunkte der Insel zur Aufnahme der Lateiner während des Krieges und zur Bändigung der Aufstände. Mit dem Satz: castella esse maximum statum et lumen insule ${ }^{4}$ ) kennzeichnen die Venezianer ihre hohe Bestimmung. Natürlich durften in den Kastellen nur Lateiner Verwendung finden. Der Ausschank von Wein war strenge verboten.

Obwohl in Kreta nur eine Handelsflotte und eine Galeere zum Sicherheitsdienst (die galea Crete) stationierte, so muBte der Herzog dem Befehlshaber des Golfes, d. h. dem Kommandanten der Schiffsflotte im Adriatischen Meere, zwei bewaffnete Galeeren stellen, die während 6 Monaten im Dienst stehen muBten. Es waren Handelsschiffe, die auf Kosten Kretas kriegsmäBig ausgerüstet und dem Besitzer mit Geld entschädigt wurden. Diese Galeeren waren nebst der Bedienungsmannschaft mit 20-30 der berühmten kretensischen Ambrustschützen bewaffnet. ${ }^{5}$ )

SchlieBlich müssen wir noch, abgesehen von anderen Unterbeamten, der comerclarii, der Zoll- und Steuerbeamten, Erwähnung tun. Die Zölle wurden gewöhnlich für einen bestimmten Zeitraum gegen Entrichtung einer fixen Summe verpachtet. So unterschied man den Zöllner am Stadttor für den Oktroi und den Zöllner am Meeresstrande.

Chanea nimmt für die Lokalverwaltung eine Sonderstellung ein,

1) Creta sacra des Flaminius Cornelius IV p. $237 \mathrm{ff}$. und Tafel u. Thomas II p. $143 \mathrm{ff}$.

2) Kapitular bei Gerland p. $102 \mathrm{ff}$. Vgl. auch das catasticum feudorum, ebenda p. 76; für die Ernennung Noirct p. 315.
3) Gerland p. 90.
4) Ebenda und Noiret p. 78.
5) Noiret Introd. p. XI. 
die sich nicht genau präzisieren läßt. Als die Ritter der Stadt im Jahre 1318 durch eine Gesandschaft in Venedig verlangten, daB sie nach Venedig possint mittere ambaxatores et capitula et defecta cum eorum rectore absque mittere Candidam, also direkt, ohne die Vermittlung Candidas, wurde dem Gesuch nur in beschränkter Weise entsprochen: Angelegenheiten, welche nur die Stadt Chanea und deren Bewohner beträfen, dürften durch eine Gesandtschaft in Venedig vorgebracht, doch müsse vorher die Regierung von Candida darum befragt werden. ${ }^{1}$ )

Wir gehen nun auf die einzelnen Zweige der Verwaltung ein, insofern uns die Akten einen Einblick in das Leben und Treiben der Inselbewohner des 14. und durch Herbeiziehung der Akten Noirets gelegentlich auch des 15. Jahrhunderts gestatten. Es liegt uns hauptsächlich daran, in verschiedenen Kapiteln die Polizei-, Militär- und Sittenverordnungen, dann Verordnungen für verschiedene Berufsklassen, für die Geistlichen, Juden und Hörigen, und für den Handel, zu gruppieren und zu sichten und im Anhang jeweilen chronologisch und nach Gruppen geordnet, unsere Proclami im Urtext folgen zu lassen.

\section{Polizei-, Militär- und Sittenverordnungen.}

Die Handhabe der Polizei, von deren Organen im vorigen Kapitel die Rede war, muBte der häufigen politischen Wirren und Aufstände wegen eine äußerst strenge sein. Die Kompetenz der Gerichte durfte in Zivilsachen 100, später 300 Dukaten nicht überschreiten, da es eine höhere Instanz in Venedig gab. ${ }^{2}$ ) In Kriminalfällen aber verfügten sie über alle Strafmittel bis zur qualifizierten Todesstrafe. Die Schlüssel zu den zwei Getängnissen carceres Ponentis und carcer Castri muBten uber die Nacht dem ducha übergeben wordon, dor auch dio Ronden kommandierte. ${ }^{3}$ )

Jedermann war der Handel und das Spiel mit den Familiengliedern der Regierung verboten. Den Beamten aller Rangstufen war der private Tauschverkehr strenge untersagt; doch scheint man sich wenig darum gekümmert zu haben, wie besonders zahlreiche Fälle von Gesetzesäbertretungen bei Noiret beweisen. ${ }^{4}$ )

Schon die Knaben unterstanden polizeilicher Aufsicht und Bestrafung, wie man aus dem interessanten Dokument vom Jahre 1369 ersieht. Raufbolden drohten Prügel und BuBe.

1) Gerland, Archiv p. 46. Vgl. auch über den Wiederaufbau Chaneas vom Jahre 1252 Tafel u. Thomas II p. $470 \mathrm{ff}$.
2) Noiret Introd. p. IX.
3) Noiret p. 50 .
4) Noiret p. 276 etc. 
Verboten war das Tragen jeglicher Waffe in der Stadt und in der Burg, auch bei festlichen Anlässen, Bedrohung und Zusammenrottung auf der Straße und in den Häusern. Im Falle eines nächtlichen Rumors sollten sich die Ritter nach Hause, die Bürger bewaffnet in den Palast begeben. Zur Nachtzeit war jedermann gehalten, mit sichtbarem Lichte ohne Säumen seines Weges zu gehen.

Bei Diebstahl- und Mordfällen ${ }^{1}$ ), die sich in Candida zu gewissen Zeiten häufig ereigneten ${ }^{8}$ ), wurde dem denunzierenden Mitschuldigen ErlaB der Strafe und oft eine Belohnung in Aussicht gestellt; in flagranti ertappte Einbrecher durften auf der Stelle niedergemacht werden; die Strafe des eingefangenen Einbrechers war Tod oder Verlust eines Gliedes.

Leute, die ihre Familie durch Spiel und schlechten Lebenswandel ruinierten, wurden öffentlich denunziert. Dem Würfelspiel scheinen die Kandioten, venezianischer Sitte gemäB, wie die zahlreichen Einschränkungen und Verbote zeigen, stark gefrönt zu haben.

Angebaute Grundstücke schützten richterliche Verbote gegen Beschädigung.

Die Erlasse für öffentliche Reinlichkeit gemahnen schon an moderne Verhältnisse, und Kreta scheint der Mutterstadt gegenüber auf höherer Stufe zu stehen. Es ist bekannt, daB es in Venedig zwischen den Häusern im Trecento noch viele Sümpfe gab, die Straßen meist nicht bepflastert waren und Küchenabfälle und sonstiger Unrat einfach auf die Straße geworfen wurden. Anders in Candida. Die Besitzer waren gehalten, den Platz vor ihrem Hause besonders am Sonnabend zu säubern und den Stadtkehricht durch vier täglich zirkulierende Wagen auf einen Platz vor der Stadt hinausfahren zu lassen. ${ }^{3}$ ) Die Hauptstraße war gepflastert. Im Jahre 1282 wurde sie an den Meisthietenden von Staats wegen für 29 Jahre öffentlich versteigert unter der Verpflichtung, daB er sie mit Stein und Kalk pflastern lasse. ${ }^{4}$ )

Die Militärverordnungen sind den bewegten Zeiten entsprechend sehr bäufig. Jeder Kandiote war vom 16.-36. Altersjahr wehrpflichtig. Wöchentlich einmal, für die Edlen am Mittwoch, für die übrigen am Sountag, fanden unter der Aufsicht der Kapitäne Schießübungen mit Armbrust, Bogen und Pfeil statt. Den Soldaten war die Heirat gestattet, sie muBten ihre Frau auf der Kanzlei aber einschreiben lassen.

1) Dekrete wegen Mordfällen auch bei Thomas, a. a. 0. p. $216 \mathrm{Nr} .177$ und p. 219 Nr. 186.

2) Vgl. in Text S. 455 Nr. $84 . \quad 3)$ Vgl. auch Noiret p. 175.

4) Thomas, Älteste Verordnungen p. 115 Nr. 23. 
Jedes Jahr einmal veranstaltete der Capitaneus Crete eine Revue der Feudati und Söldner. Die villani wurden im Jahre 1416 davon befreit, weil es unnütz und gefährlich erschien, so große Haufen zu versammeln. ${ }^{1}$ ) Im Jahre 1349 wurden die Lasten zur Aushebung eines kretensischen Heeres gegen die Türken so verteilt, daB der Staat 1/3 übernahm, die übrigen $2 / 3$ durch einen aus den vier Territorien Candida, Chanea, Rethymo und Sithia gewählten, aus 12 Mitgliedern bestehenden Ritterrat auf die Bewohner verteilt wurden..$\left.^{2}\right)^{3}$ )

Der Handel scheint auch den Kretern des 14. Jahrhunderts großen Verdienst eingebracht zu haben. Wenn derselbe auch hinter den unermeBlichen Einkünften der GroBkaufleute im Mutterlande zurückblieb, so beweisen doch die Verordnungen dieses Kapitels, daB das 14. Jahrhundert, d. h. wohl nur die Zeit vor 1363, vor der groBen Revolution, für Kreta eine Periode zeitweiligen Wohlstandes bedeutete, wobei neben solidem Reichtum auch nur äußeres Schaugepränge den Anschein von Wohlhabenheit erwecken mochte.

Bei Hochzeitsfestlichkeiten muB es zuweilen hoch hergegangen $\left.\operatorname{sein}^{4}\right)$; deshalb werden alle Festgelage einen Monat vor und nach der Hochzeit untersagt. Festliche Anlässe, wo die Leute sich ungescheut zusammenfinden konnten, boten auch die beste Gelegenheit zu Verschwörungen, und so hat die Regierung Familienfeste auf den Tag und auf eine möglichst geringe Zahl Eingeladener beschränkt.

Hand in Hand mit dem zunehmenden Reichtum entfaltete sich Luxus und orientalische Pracht. Die Kretenserin erschien in Samt und Seide, in reich mit Gold und Perlen besetzten Kleidern, in fein gestickten Überwürfen, mit hochaufgeputztem Haar. Während in den Städten Deutschlands und der Schweiz erst viel später Kleidermandate publiziert werden, erläBt die Regierung in Kreta, wie natürlich auch in Venedig, schon im Beginn des 14. Jahrhunderts strenge Luxusver-

1) Noiret p. 249.

2) Gerland, Archiv p. 56.

3) Um die Truppen zu verstärken, erteilte man im Jahre 1454 geflohenen Verbrechern, ausgenommen Rebellen und Mördern, gegen geleistete Kriegsdienste in Nigroponte vel in Durachio völlige Amnestie. Noiret p. 443.

4) Noiret bringt auf p. $276 \mathrm{ff}$. ein interessantes Hochzeitsdekret aus dem Jahre 1420: Da die Männerwelt sehr anspruchsvoll geworden und die Fltern der Braut dem Scheine zuliebe die Aussteuer und den Hochzeitsschmaus ins Luxuriöse steigern, so daB viele der armen Geschöpfe cum dignis lacrimis et planctibus ipsarum in ein Frauenkloster gesteckt werden, müssen die Ausgaben der Schwiegereltern durch Verfügung auf höchstens 1600 Dukaten herabgemindert werden. Virgines populares parentelam contrahentes cum nobilibus dürfen als Mitgift mitbringen, was ihnen beliebt. 
bote für Kinder, Männer und Frauen lateinischer, griechischer und jüdischer Nation. ${ }^{1}$ )

In der Bestimmung über die Leichenbeisetzung und in dem eingangs dieses Kapitels erwähnten Reinigungserlasse finden sich deutliche Spuren sanitärer Vorschriften. Im Jahre $1388^{2}$ ) erhielten die Kretenser einen Arzt - man hatte deren zwei verlangt -, dem die Feudati ein Jahresgehalt von 300 Perpern bezahlten. $\left.{ }^{3}\right)^{4}$ )

Von humanem Geist zeugt die fürsorgende Teilnahme der Regierung am Schicksal des ausgesetzten Kindes Christina. Das strenge Vorgehen Venedigs gegen Sittendelikte wirkte auch auf Kreta hinüber, wo Bordellwirtschaft und Vielweiberei mit Buße und Gefängnis belegt wurden. ${ }^{5}$ )

\section{Urkundentext.}

\section{a) Polizeiliche Vorschriften. ${ }^{6}$ )}

Die XVIII. ianuarii [indic. VII. 1339].

Regest. 59. Niemand darf von nun an facere aliqua credentia alicui de familia dominorum consiliariorum nec cum eis ludere ad aliquem ludum nec eis permittere ludere in sua taberna bei einer Buße von 3 hypp.

Die XXII. iulii [indic. XIII. 1360].

111 Cl. f. p. p. ${ }^{7}$ ) Iohannem Marino g. quod si quis haberet petere aliquid a Capellano seu socio domini duche uel capitaneo carcerorum uel quocunque alio de familia dicti domini duche uel uellet

1) In Venedig wurden schon im 13. Jahrh. Luxusverbote erlassen. Vgl. P. G. Molmenti, Venedig und die Venezianer p. $335 \mathrm{ff}$. Auch Noiret bringt p. 109 (1400) ein Kleidermandat.

2) Noiret p. 22

3) Da die Zentralregierung ihnen oft unfähige Leute als Ärzte zusandte, verlangten im Jahre 1462 die Feudati, daB sie den Arzt, den sie bezahlen, auch selber anstellen dürften. Noiret p. 476. Für Chanea wird schon für das Jahr 1300 ein Arzt erwähnt. Commem. Lib. I Nr. 38.

4) Im Jahre 1478 Wahl eines Arztes für Rethimo mit 130 Perpern Gehalt. Noiret p. 541.

5) Da es häufig vorkam, daB junge Leute ehrbare Jungfrauen auf offener Straße überfielen und schändeten, un sich auf diese Weise die elterliche Erlaubnis zur Heirat mit der Vergewaltigten zu erzwingen, erlieB der Senat auf das Ansuchen der Feudati hin im Jahre 1462 ein Gesetz, laut den solchen Missetätern beide Hände abgehackt werden sollten. Noiret p. 478. Dasselbe in Creta sacra des Flaminius Cornelius II 390 u. 391.

6) Das Gleichartige gruppiert und chrocologisch geordnet. Für dic Nummern vgl. Gerland, Archiv p. 18.

7) Abkürzung für Clamatum fuit publice per. . . gastaldionem. 
dicere quod aliquis predictorum accepisset ab eo quicquam per modum .... ${ }^{1}$ ) seu per quemcunque alium modum, debeat conparere usque ad diem tertium proximum coram domino ducha et dicere quicquid uult, et dominus ducha faciet sibi fieri expedite debitam satisfactionem.

Die III. iulii [1369].

64 Cl. f. p. in lobio et extra portas ciuitatis Candide ac in iudaica Candide per Iohannem Marino g.: cum dominatio non intendat, quod aliquis de familia sua possit contrahere aliqua debita ullo modo, dominus ducha et eius consilium faciunt notum omnibus et mandant, quod decetero nullus audeat mutuare aliquos denarios uel dare seu uendere aliquid in credentia alicui de familia domini duche et dominorum consiliariorum, nec debeat ab eis recipere nomine pignoris uel in saluo arma, uestes, seu aliquam aliam rem, nec debeat ipsos recipere fideiussores de alieno debito cum cartis uel cedulis aut scripturis, nec debeat ludere cum eis ad aliquem ludum. Et sit notum omnibus, quod si aliquis eis mutuanerit uel dederit seu uendiderit aliquid in credentia, uel fecerit aliud contra predicta, non fiet sibi ius per dominium nec per iudices in predictis. Et pignera si qua receperint, restituentur absque solutione et que ipsi famuli perdiderint in aliquo ludo, similiter restituentur eis, absque ulla satisfactione. Et in predictis non intelligantur socii domini duche.

Die II. nouembris [indic. III. 1317].

15 Cl. f. p. p. Petrum Uido g., cum alias facta fuerint banna, in quibus erant pene que uidebantur signorie nimis graues, dominus ducha et eius consilium faciunt notum, quod ipsi correxerunt et ordinauerunt dicta banna modis et conditione infrascriptis mandantes, quod omnes illa banna debeant obseruari.

16 Item imprimis, quod nulla persona audeat portare curtellum feritorum ${ }^{2}$ ) de die uel de nocte sub pena ypp. quinque pro quolibet, cui reperiretur, et quod nullus audeat portare spatam uel alia arma maiore mensura sub pena ypp. XXV pro quolibet, cui reperiretur.

17 Item quod nullus audeat extrahere curtellum feritorum contra aliquam personam super plathea uel ruga maestra Candide, uidelicet a porta maiore ciuitatis usque ad angulum stationis Paganicii speciarii sub pena ypp. quinquaginta, et si extraheret spatam uel alia arma maiore mensura, cadat ad penam ypp. $\mathrm{C}$, et si in aliis locis tam in ciuitate quam in burgo aliquis extraheret cultellum, cadat ad penam ypp. XXV, et si extraheret spatam uel alia arma maiore mensura,

1) Fehlt ein Wort.

2) Den Domini de nocte war es natürlich gestattet. S. Gerland, Archiv S. 97 u. 
cadat ad penam ypp. L. Et si esset feudatus qui extraheret de dictis armis, uidelicet feudatus contra feudatum, cadat ad penam duplicem de predictis penis secundum modum predictum.

18 Item quod nulla persona contraheret super plathea uel ruga maestra, uidelicet a porta maiore ciuitatis Candide usque ad angulum stationis Paganicii speciarii per longum et passibus XXV per tressum inter hos predictos confines uel ubi teneat stationem, audeat in domo sua uel statione recipere uel tenere arma alicuius persone sub pena ypp. quinquaginta pro quibuslibet armis offensionis qualibet uice qua contrafecerit, de qua pena accusator habere debeat medietatem, si per eius accusationem ueritas cognoscetur, et reliqua medietas deueniat in comune.

19 Item si aliquis rumor uel briga sonabit de cetero in plathea, quod omnes feudati et filii feudatorum debeant statim ire ad domos suas et inde non rece[dant] ${ }^{1}$ ) usque ad uoluntatem signorie sub pena ypp. ducentorum pro quolibet contrafaciente et plus ad uoluntatem signorie.

20 Item quod quandocunque aliquis rumor uel briga sonaret in plathea sicut dictum est, omnes burgenses, mercatores et alii habitatores cuiuscunque conditionis sint, debeant et teneantur se reducere cum suis armis ad palatium ad signoriam sub pena ypp. ducentorum pro quolibet burgense et quolibet mercatore, ypp. quinquaginta pro quolibet alio alterius conditionis.

21 Item si aliquis rumor uel briga sonaret alibi quam in plathea, et dominus ducha faceret sonare campanam ad martellum, quod ounnes feudati statim et filii feudatorum debeant statim ire ad domos suas et inde non recedere usque ad uoluntatem signorie sub pena eis [imposita supra et] ${ }^{2}$ ) similiter omnes burgenses mercatores et alii homines habitatores dicte ciuitatis tunc teneantur se reducere cum suis armis ad palatium ad signoriam sub dicta pena eis imposita supra.

Die XX. aprilis [indic. II. 1318].

$58 \ldots \ldots$. Item ${ }^{3}$ ) quod nulla persona audeat portare cultellum de ferro sub pena ypp. decem de die et sub pena ypp. uiginti de nocte et quod non possit portare spatam uel cultellum uel alia arma maioris mensure sub pena ypp. uiginti quinque de die et sub pena ypp. quinquaginta de nocte. Et qui contrafecerint de dictis armis, cadant in dupplicem penam.

Et similiter non possit aliqua persona portare panceriam uel coraziam sub pena ypp. uiginti et ceruelleriam sub pena ypp. quinque et

1) Rasur. 2) Rasur. Konstruktion v. unten.

3) Zu der Wiederholung des Vorigen noch dieser Zusatz. 
bucculerium uel..... sub pena ypp. quinque, et illi quibus reperirentur de dictis armis, perdant ea etiam.

Die X. febrarii [indic. VI. 1338].

31 Cl. f. p. p. Georgium Cornario g. sub lobio, ad malcantonem et ante ecclesiam sancti Marci, quod magnificus dominus Iohannes Sanuto ducha Crete et eius consilium mandat infrascripta banna et ordinamenta obseruari.

32 Imprimis quod aliquis non audeat facere aliquam congregationem in domo sua de gente de pluribus tribus personis ultra suam $\ldots^{1}$ ) sub pena ypp. mille illi qui faciat dictam congregationem, et ypp. centum pro quolibet illorum qui se reducerent uel congregarint ad domum alicuius. Et qui accusabunt contrafacientes......

37 Item quod nullus feudatus uel filius feudati amodo audeat ire de nocte pedes uel eques post sonum tertie campane sub pena ypp. uigintiquinque pro quolibet contrafaciente et qualibet uice et nichilominus circabuntur et si reperientur eis arma, soluant pro eis penam ordinatam. Et quod nulla alia persona amodo audeat ire de nocte pedes uel eques sine igne qui appareat, post sonum tertie campane sub pena ypp. duorum et nichilominus circabuntur et si reperientur eis arma, soluent pro eis penam ordinatam. Intelligendo quod non possint nec debeant stare, nec sedere super banchis uel alibi cum igne, sed ire ad uiam suam solum modo, et si contrafecerint, cadant ad dictam penam, ac si reperirentur sine igne.

Die VIII. mensis octubris [indic. VII] de mandato magnifici domini Iohannis Mauroceno ducha Crete et eius consilii presens bannum fuit iterato publice proclamatum ad memoriam et cautelam rei maioris.

Item quod nulli amodo audeant equitare per ciuitatem uel burgum ultra quattuor simul sub pena ypp. decem pro quolibet contrafaciente et qualibet uice non intelligendo, si irent uel equitarent foris ad casalem uel ad paesam ${ }^{2}$ ) uel cum dominatione.

Die XXIIII. ianuarii [1319].

39 Cl. f. p. p. Riçardum g., quod cum Nicolaus Pecicha, uillanus Iohannis Tetandi, fuerit accusatus de morte Iohannis de Foraria, habitatoris in casali sancti Iohannis Karacha, et clamatum fuerit, quod conpareret ad faciendum suam excusationem, qui non conparuit, ita quod remansit in banno, qui etiam diffamatur de pluribus aliis maleficiis et furtis et forciis, dominus ducha et eius consilium faciunt notum,
1) Ein Wort unleserlich.
2) Hs: paessam. 
quod quicunque dabit dictum Nicolaum Peçicha uiuum in forcium signorie, habeat a comuni ypp. $L$ et sciant omnes, quod illi qui eum interficerent, non haberent a comuni aliquam penam, quia ipse est forbannitus.

Die XVIII. iulii [indic. I. 1334].

32 Cl. f. p. p. Petrum Uido g. quod cum alias publicati fuerint ordines infrascripti capti in consilio rogatorum ut obseruari deberent, et ad dominationis aures peruenerit, quod dicti ordines non seruantur, dominus ducha et eius consilium ipsos ordines faciunt publicari, mandantes quod decetero quelibet persona ipsos ordines debeat obseruare, quorum forma talis est.

Capta fuit pars in consilio rogatorum, quod propter homicidia, percussiones et alia multa mala que fiunt in panegiriis, decetero illi qui iuerint ad ista panegiria, scilicet quibus licitum est ire, non possint ferre aliqua arma sub pena ypp. duorum pro singulis armis, de quibus medietas ueniat in comune et altera medietas in accusatorem. Item quod nulla persona decetero audeat portare uinum in panegiriis pro reuendendo, sub pena ypp. quinque pro qualibet persona contrafaciente, de quibus medietas.... Item quod decetero nullus feudatus uel filius feudati nec burgensis, homines burgensium uel filius burgensis debeat ire ad aliqua panegiria, sub pena ypp. decem pro quolibet, de quibus accusator.... Et ad hoc, quod predicta omnia debeant obseruari, capitaneis et castellanis iniungetur, quod mittant ad panegiria suorum districtuum seruientes ad inquirendum contrafacientes.

Die XXV. marci [indic. III. 1334].

11 Cl. f. p. p. Pe[trum Uido] g., cum quidam infantulus hodie mane repertus fuerit mortuus ad marinam extra castellum uersus $\mathrm{Ma}$ çamba, dominatio mandat et notum facit, quod si quis denunciauerit dominationi cum ueritate, quis uel qua dictum infantulum in dicto loco posuerit et cum ponente fuerit uel conscius fuerit proiectoris ipsius, habebit de camera comunis ypp. centum et tenebitur de credentia, et si fuerint plures conscii dicti sceleris ${ }^{1}$ ) siue facinoris et aliquis uel aliqua eorum, excepta matre uel tractatrice dicti sceleris ${ }^{2}$ ), denunciauerit eos dominationi, ipse denunciator sit absolutus de pena quam ceteri conscii ipsius incurrerent et habebit de camera comunis ypp. L et tenebitur de credentia.

Die III. maii [indic. VI. 1338].

44 Cl. f. p. p. Georgium Cornario g., quod cum modo nuper Iohaunes de Bancha habitator Candide fuerit percussus super plathea
1) $\mathrm{Hs}$ : seleris.
2) Hs: selleris. 
taliter, quod datus est de periculo, de qua percussione Petrum Binelli de Florencia scribam ligni Francisci Bartholomei dicitur esse partecipem et culpabilem, dominus ducha et eius consilium mandant, quod aliqua persona amodo non audeat tenere dictum Petrum in domo sua sub pena ypp. quingentorum, sed si aliquis eum haberet in domo uel loco suis, debeat ipsum dominationi presentare. Insuper quod aliqua barcha uel nauigium uel patronus uel alia queuis persona non audeat nec debeat ipsum Petrum leuare nec ipsum conducere et ferre extra insulam sub pena predicta ypp. quingentorum. Insuper quod aliqua persona tam feudatus quam alia queuis persona non debeat nec audeat ipsum Petrum tenere ad aliquem locum suum positum tam in ciuitate quam foris nec ad casalem suam nec dare ipsi aliquod auxilium, consilium uel fauorem uel equum sub pena predicta. Et quicunque accusabit... Et hoc bannum proclamatum fuit in tribus locis, uidelicet sub lobio, in burgo et in ripa.

Die III. iunii [indic. I. 1334].

24 Cl. f. p. p. Iohannem Gysi g., cum nocte nuper elapsa desgardenata et aperta fuerit porta magaçeni, in quo uenditur sal comunis, et in dicto magaçeno desgardenata fuerit capsa, in qua repositi erant denarii habiti de uendicione salis in certa quantitate, et de ea extracti et accepti fuerint denarii qui erant in ea, que capsa clausa et conclauata erat tribus seraturis, dominatio mandat et notum facit, quod si quis denunciabit dominitioni illum uel illos, qui predicta commiserunt et fecerunt ita, quod per eius denuntiationem ueritas haberi possit, ita, quod ille uel aliquis illorum, qui predicta commiserunt, capiantur et ueniant in fortio dominationis, habere debeat de camera comunis ypp. quinquaginta, et si ille uel illi qui dictum furtum et disgardenationem commiserunt, non possint capi, dummodo constaret dominationi ipsum uel ipsos predicta commisisse, accusatore denunciante eum uel eos usque ad diem domenicum proximum, habere debeat accusator de camera comunis ypp. uigintiquinque, et si aliquis de illis qui predicta commiserunt, si plures fuerint, socios suos qui ad dictum furtum committendum fuerint, denunciabit ita, quod ipsi uel illorum aliquis deueniat in fortio dominationis, sit absolutus ab omni pena quam pro dicto furto et desgardenatione incurrisset.

Die XXVIIII. decembris [indic. XIII. 1344].

80 Cl. f. p. p. Georgium Cornario g. in lobio et extra portas quod cum die ueneris XXIIII mensis decembris presentis circa horam dimidie noctis IIII $^{\circ}$ persone armate spatis, arcubus et sagittis ${ }^{1}$ ) apperuerint

1) Hs: sagitis. 
uiolenter molendinum ser Iohannis Fradello dictum Ochrea, positum in districtu Pediade, et percusserint Leonardum de Uigontia dictum Margariti qui erat in dicto molendino, et cohoperuerint cum spaliaça ipsum Leonardum, uxorem eius et duos eius filios, ligatis eorum manibus, donec derobarent totaliter ipsum molendinum unde abstulerunt XIII mensuras frumenti cum saccis et quedam alia, prout de predictis facta est querimonia castellano Pediade qui hec dominio denotauerit, et hec enormitas tante audacie sit grauis dominio, quantum debet, ideoque desideret noscere, qui fuerunt illi qui dictum raubarie maleficium perpetrarunt, et habere eos in suo fortio, domini consiliarii et rectores faciunt notum et mandant... [der Ankläger erhält 200 Perpern, der denunzierende Mitschuldige 100 Perpern und die Freiheit].

Die XXVIII mense decembris [indic. X. 1356].

84 Cl. f. p. p. Bartholomeum de B. g., quod cum multe querelle facte fuerint dominio de aliquibus latronibus, qui euntes de nocte per ciuitatem Candide intrant furtiue et malo modo in domos nobilinm et aliarum personarum, furantes quicquid possint de ipsis domibus, dominus ducha et eius consilium pro cessatione malorum et destructione malefactorum faciunt notum omnibus et mandant, quod quicunque habitator dicte ciuitatis Candide reppererit decetero de nocte in domum suam aliquam personam ingressam intra ipsam, dominus uille ipsius possit illam personam uel personas capere et intromittere, et si ille persone uoluerint se defendere, et in hoc casu percussi fuerint uel interfecti, percussores eorum de hoc nullam penam debeant supportare, et si hoc modo captus fuerit et presentatus dominio uiuus aliquis malefactor in homicida, habeat a comuni ille qui eum presenta[uerit] ypp. quinquaginta, si ille malefactor fuerit adiudicatus morte; si uero dictus malefactor fuerit adiudicatus perdere membrum uel membra, habeat a comuni ille qui cum presentauerit ypp. uigintiquinque, et si plures malefactores fuerint sic capti et presentati, tantum habeat presentator eorum pro unoquoque ipsorum quantum specificatum in quolibet casu predicto, et hoc duret amodo usque per totum carnispriuium proximum uenturum.

Die III. mensis iunii [indic. VIII. 1370].

$124 \mathrm{Cl}$. f. p. p. Iohannem Gradonico g. in lobio et extra portas ciuitatis Candide, quod cum nobilis Franciscus Michael perdiderit unum anulum auri cum lapillo nomine Karniola, in quo quidem anulo sunt notate alique littere, dominus ducha et eius consilium et dominus capitaneus Crete faciunt notum omnibus et mandant, quod quicunque nabet dictum anulum, debeat illum manifestare et presentare, alioguin imputabitur sibi pro furto. 
Die VI. decembris [1369].

98 Cl. f. p. in lobio et extra portas ciuitatis Candide etiam in pluribus partibus burgi Candide per Iohannem Marino g.: cum ad aures dominationis peruenerit, quod aliqui pueri congregantur in certis locis positis in burgo et extra burgum Candide et ibi se ponunt in duabus postis pugnantes et preliantes ad inuicem prohicientes lapides cum sarandegolis et cum propriis manibus percutientes et ledentes se inuicem et taliter, quod plures ex eis uulnerati fuerunt et unus mortuus est ex percussione sibi illata ibi, dominus ducha et eius consilium intendentes, quod huiusmodi prelium lapidum non debeat fieri amplius, sed cesset omnino, faciunt notum omnibus et mandant, quod decetero nullus audeat in aliqua parte burgi uel in aliquo loco extra burgum ponere se ad tale prelium lapidum cum aliqua assunantia puerorum et prohicere lapidem uel lapides cum sarandegolis uel cum manibus propriis contra aliquam personam magnam uel paruam, sub pena inferius annotata, uidelicet, quod si illi qui contrafecerint, erunt etatis annorum XIII uel inde supra, uerberentur apud quintanam et soluant etiam ypp. $\mathrm{V}$ pro quolibet et qualibet uice, si uero dicti contrafacientes erunt minoris etatis, uidelicet $a b$ annis XIII infra, uerberentur in loco predicto pro qualibet uice qua contrafecerit, et si fuerit caput, uerberetur sicut predicitur et soluat ypp. decem. Et hec committantur dominis de nocte....

Die II. mensis aug. ${ }^{\text { }}$ [1337].

14 Cl. f. p. p. Petrum Uido g., quod cum Antonius, filius quondam ser Iohannis Artaroti, non teneat bonam uiam in facienda facta, sed uadat quantum faciendum debita et emptiones non licitas et ludendi continue, que uertantur in dannum maximum et iacturam suorum fratrium, a quibus non est diuisus, dominus ducha facit notum omnibus et mandat, quod nulla persona amodo debeat dare, mutuare ac uendere modo aliquo rem aliquam siue denarios dicto Antonio Artaroti, nec aliquis debeat ludere cum ipso Antonio ad aliquem ludum, ad quem uadunt denarii, et quicunque dederit, mutuauerit aut uendiderit amodo aliquid dicto Antonio, amittit totum id quod sibi dederit, mutuauerit aut uendiderit, et qui cum ipso luxerit ${ }^{1}$ ), reddet totum id quod sibi lucratus fuerit, si sibi lucratus fuerit aliquid. Insuper quod notarius aliquis amodo non debeat facere cartam aliquam, aut admittere precem de faciendo cartam aliquam uel contractum, qua dictus Antonius in aliquo obligetur, sub pena ad uoluntatem dominationis, et nihilominus carta sic confecta nullius erit ualoris. ${ }^{2}$ )

1) Venez. für luserit.

2) Diese Verordnung kehrt in ähnlicher Form immer wieder. 
Die ultimo aug. ${ }^{\mathrm{i}}$ [indic. V].

15 Simile bannum factum et proclamatum fuit per Petrum Uido g. suprascriptum pro Michaele, filio indiuiso Nicolai Carandino.

Die VII. septembris [indic. VI].

16 Simile bannum factum et proclamatum fuit per gastaldionem suprascriptum pro Iohanne Gysi, filio quondam nobilis uiri Marci Gysi.

Die XIII. nouembris [indic. VI].

16 Simile bannum factum et proclamatum fuit per dictum gastaldionem pro Leonardo Truno, filio quondam Michaelis Truno.

Die II. nouembris [indic. VI. 1337].

21 Cl. f. p. p. Petrum Uido g., quod nullus audeat decetero ludere ad aliquem ludum taxillorum, in quo uadant denarii, alio quam sub lobio sub pena ypp. quinque pro quolibet et qualibet uice. Et committantur aduocatoribus comunis qui inquirant de contrafacientibus...

Die XVIII. ianuarii [indic. IIII. 1350].

13 Cl. f. p. in lobio et extra portas ciuitatis Candide per Bartholomeum de Bonfilio g., cum ad aures dominationis peruenerit, quod plures frequenter(? $\left.{ }^{1}\right)$ se reducentes ad aliqua loca extra consueta ludunt ad taxillos, et alii etiam ludunt ad alios diuersos ludos ualde inhoneste consumentes eorum substantiam, dominus ducha et eius consilium mandant pro bono suorum ciuium, quod decetero nemo audeat in ciuitate uel burgo aut extra per quinque milliaria distantia a ciuitate ludere in aliqua statione uel domo aut aliquo alio loco occulto uel non occulto ad açarum (sic) seu alium ludum taxillorum uel aliarum aut ad postadelles siue ad aliquem alium ludum cuiuscunque conditionis existat ultra ypp. decem pro quolibet in die preterquam in lobio et in Malcantone et in Ruga que remanet media inter lobium et Malcantonem, ita tamen, quod etiam ibi non possit fieri ludus intra stationem uel domum, et insuper in hiis locis exceptatis nemo audeat ludere ad lumen sub pena ypp. uigintiquinque pro quolibet ludente contra hunc ordinem et ypp. centum illi cuius esset statio seu domus seu locus ubi foret contrafactum ordini suprascripto, seu illi qui haberet ad affictum dictam stationem uel domum uel locum et qualibet uice....

Die XXIIII. iunii [indic. IV. 1366].

13 Cl. f. p. p. Iohannem Marinum g. in lobio et extra portas ciuitatis, quod cum Nicolaus de Priolis pelliparius non bene dispositus defectu discretionis faciat facta sua male atque sinistre, ducens uitam inhonestam, consumens pauperitatem suam et contrahens debita, obli-

1) Unleserlich. 
gando se tamquam principalem et pleçium aliis in non modicum dannum et preiudicium uxoris et filiorum suorum, dominus ducha et eius consilium faciunt notum omnibus et mandant, quod decetero nulla persona debeat mutuare uel in saluo seu commenda dare aliquid dicto Nicolao, nec uendere ei aliquid in credentia nec facere sibi eundem Nicolaum debitorem principalem uel pleçium alicuius sub aliqua obligatione, sciendo quod quicunque deinceps contrafecerit huic banno, amittet totum id, quod dicto Nicolao dederit contra hunc bannum, et omnis obligatio quam ipse Nicolaus fecerit, nullius erit ualentie uel uigoris nec inde fiet ius alicui contra Nicolaum predictum.

Die X. iunii [1369].

61 Cl. f. p. p. suprascriptum g. ${ }^{1}$ ), quod aliqui conantur accipere de domibus aliorum famulos et ancillas seu baiulas firmatas ad seruiendum patronis ipsarum domorum in sinistrum et grauamen non modicum eorum, de quo sepius oriuntur scandala et discordie inter personas, dominus ducha et eius consilium, uolentes in hoc remedium apponere, faciunt notum omnibus et mandant, quod decetero nullus audeat per se uel per alium accipere famulum nel famulam aut baiulam alicuius persone sine consensu illius, cum quo erit firmata ad seruiendum, sub pena ypp. uiginti quinque pro quolibet et qualibet uice.

Item quod nullus famulus uel ancilla seu baiula que firmata erit ad seruiendum alicui certo tempore, audeat recedere de domo illius persone, cui tenebitur seruire, sine licentia sui patroni, nisi prius conpletum $^{2}$ ) fuerit tempus, pro quo tenebitur ei seruire, sub pena standi in carcere per mensem unum et nihilominus post complementum mensis teneatur itero redire ad domum sui patroni et seruire ibi pro toto tempore quo tenebitur secundum formam pacti facti secum. Et hec committantur aduocatoribus comunis ...

Die XXVII. februarii [indic. XIII. 1345].

83 Cl. f. p. p. Georgium Cornario g. in lobio, in ianua sancti Marci et extra portas, quod cum sit datum intelligi dominio, quod sunt ceteri equi euntes per seminationes et uineas aliorum facientes magnum dan. num, et nescitur quorum sunt, dominus rector et eius consilium faciunt notum et mandant, quod illi quorum sunt equi predicti, debeant eos facere capi infra octo dies et detineri, ne uadant dannificando per loca aliorum, alioquin dominatio ordinabit, quod interficiantur.

Die XX. octubris [indic. III. 1349].

46 Cl. f. p. p. Iohannem Marino g., quod nulla persona uel bestia magna uel parua intret uel dannum faciat in aliqua uinea, iardino uel
1) Iohannem Marino.
2) Hs: conplectum. 
territorio ${ }^{1}$ ) seminato blado, fossadatis uel clausis sub pena ypp. duorum pro qualibet persona et bestia grossa et quolibet porco seu scrofa et quolibet clapo pecudum seu aliarum bestiarum minutarum et nihilominus soluendi dannum.

Item quod nulla persona uel bestia grossa uel minuta faciat dannum uel pasculet in territorio seminato blado non fossadato seu non clauso sub pena ypp. unius nec in pasculis, pratis uel terris uacuis aliorum sub pena grossorum sex pro qualibet persona et bestia grossa, et quolibet porco uel scrofa et ypp. duorum pro quolibet clapo pecudum seu aliarum bestiarum minutarum et soluendi dannum. Intelligendo et declarando clapum pecudum uel bestiarum minutarum fore uigintiquinque uel inde supra, et quod a XXV infra iusticiarii procedant prout sibi uidebitur fore iustum.

Item pro quocunque cane qui intrauerit tempore uuarum in aliquam uineam, debeat soluere ille, cuius erit dictus canis, dannum et grossos sex pro pena qualibet uice, exceptis canibus itinerantium, uenatorum et paysatorum, quoniam transeunt per uiam illi quorum sunt uel uenantur uel paysant. Et si accusator fuerit...

Die XXVI. aug. ${ }^{i}$ [indic. U. 1364].

2 Cl. f. p. p. suprascriptum g. $^{2}$ ) in lobio et ante portas ciuitatis Candide, quod nulla persona tam soldatus quam alii cuiuscunque conditionis existat, audeat intrare in uineam uel iardinum alicuius persone absque licentia et consensu patronorum, nec alicui persone [licitum $s i t^{3}$ ) in porta ciuitatis uel in aliquo loco accipere fructus uel aliquid aliud sine suo uelle, nec dannum aliquod facere alicui persone, sub pena soluendi duplum ...

Die XV. nouembris [indic. XIIII. 1360].

33 ... [Der erste Abschnitt handelt von den Verunreinigungen im allgemeinen in der Stadt Candida.]

Item quicunque habet aliquam terram suam uacuam, in qua proicerentur $^{4}$ ) uel iam essent proiecte quisquillie uel aliquid aliud fetidum, debeat ipsam terram mundari facere amodo usque ad mensem Maii proximi uenturi sub pena ypp. decem pro qualibet appositione huiusmodi, et si contrafecerit, soluta dicta pena, adhuc teneatur ipsam terram mundari facere, et tunc usque ad mensem unum proximum sub eadem pena et sic successiue, donec hoc obseruetur, et ipsam mundam tenere et conseruare, et si uoluerit ipsam mundari facere, teneatur ipsam ita murare seu serare usque ad predictum mensem maii, quod
1) $\mathrm{Hs}$ : teritorio.
2) Iohannem Marino.
3) [ ] fehlt in der Hs.

4) $\mathrm{Hs}_{s}$ : prohicerentur (so immer). 
in ea non proiciantur quisquilie uel aliquid aliud de predictis sub pena ypp. decem, et si non obseruauerit, teneatur ut supra de aliis et iste pene diuidantur per tertium ...

34 Item cum ordinatum sit, quod quam cito fieri poterit fiant seu emantur quatuor carete cassis fulcite, pro quibus adducendis salarientur persone XII ad hoc apte, dominus ducha et eius consilium mandant, quod nulla persona audeat proicere extra portam suam in aliqua parte ciuitatis quisquilias, terram, letamen uel immunditiam aliquam nec aliquid fetidum uel mortuum, sed in unaquaque ${ }^{\mathbf{1}}$ ) domo quisquilie siue et alia huiusmodi [remaneant] ${ }^{2}$ ), donec illuc adducantur dicte carete, quarum due deputentur ad partes leuantis ciuitatis, et relique due ad partem ponentis, circumeundo ${ }^{3}$ ) cotidie cales et contratas, sonando unum cornum pro unaquaque careta, ut quilibet sentiat ipsas adduci et tunc in cassis dictarum caretarum unusquisque possit et debeat ponere antedicta que per dictas caretas ${ }^{4}$ ) et adductores eorum portari et proici debeant extra ciuitatem ad suprascriptum locum de Megali Coprea.

35 Item quod quolibet die sabbati omnes habitatores ciuitatis debeant facere scopari et mundari ante portas suarum habitationum et stationum suarum, in tantum quilibet quantum extenduntur sue domus et stationes, ita quod omnes uie et cales munde remaneant, quod facere debeant, quando uie et cales sunt sicce luto facto ex pluuia; quisquilie uero inde coadunande reponantur in aliquo loco uicino ${ }^{5}$ ), donec eas inde leuent antedicte carete, sciendo et expresse intelligendo, quod per dictas caretas non debeant leuari et portari letamen factum ab equis et saumeriis de stabullo alicuius, quicunque autem contrafecerit et proiecerit extra suam portam quisquilias et aliquid aliud ...

36 Item quod predicti adductores suprascriptarum caretarum debeant cotidie dictas caretas per omnes uias et cales adducere, accipientes et portantes quisquilias et alia suprascripta, et ea proicentes ad suprascriptum locum de Megali Coprea, sub pena grossorum XII, qualibet die pro quolibet defficiente seu contrafaciente, que pena diuidi debeat sicut superius continetur.

Expense uero fiende pro dictis caretis et ipsarum adductoribus, quod est utilissimum et precipue sanitati, soluantur per omnes habitatores ciuitatis Candide secundum qualitatem et facultatem cuiuslibet non inponendo alicui ultra grossas quatuor et minus grosso uno in anno, excludendo ab ista impositione omnes illas personas pauperrimas,
1) Unleserlicb.
2) [ ] fehlt in der $\mathrm{Hs}$
3) Unleserlich.
4) Hs: karetas.
5) Unleserlich. 
que uiderentur dominio excludende. Uerotamen quantum deducetur seu non inponetur occasione impossibilitatis dictarum personarum pauperrimarum, ut dictum est, tantum debeat inponi et superaddi aliis ultra grossas IIII ${ }^{\text {or }}$ et ressiduum solutionis dictarum expensarum solui debeat per comune. ${ }^{1}$ )

Die XXX. aug. ${ }^{\mathrm{i}}[1369]$.

79 Cl. f. p. p. Nicoletum de Molino g. in lobio et extra portas ciuitatis Candide, cum alias factum fuerit bannum, quod omnes debentes dare comuni denarios pro frumento eis dato in tribus getis factis hinc retro, deberent soluere id quod dare debebant usque per totum mensem augusti presentem, notificando eis, quod omnes qui non soluerant primum et secundum getum, habebantur pro caducis ad penam insertam in banno alias facto, et propter occupationes instantium uindemiarum plures non potuerint soluere dictum debitum infra terminum antedictum, dominus ducha et eius consilium faciunt notum omnibus, quod elongant dictum terminum et mandant, quod omnes debentes dare comuni denarios pro frumento predicto, debeant soluere totum id, quod dare debent usque ad medium mensis septembris proxime uenturi sub pena grossi unius pro quolibet ypp., et sit notum omnibus, quod omnes qui non soluerunt primum et secundum getum, habentur pro caducis ad penam insertam in primo banno alias facto, et nihilominus ${ }^{2}$ ) ultra illam incurrent etiam penam presentem, si non soluerint ad terminum antedictum, et hic terminus erit ultimus et peremptorius.

\section{b) Militärische Verordnungen.}

Die XXVI. febrarii [indic. X. 1341].

41 Cl. f. p. p. Georgium Cornario g., quod dominatio intendit parare exercitum iturum ultra scalas ${ }^{3}$ ), cum quo ire debet unus ex dominatione, quando uidebitur et sicut uidebitur, et quod omnes milites et feudati sint prompti et parati equis et armis ad beneplacitum et mandatum signorie scientibus uniuersis quod dominatio intendit eligere ${ }^{4}$ ) et nittere in dicto exercitu omnes illos qui ... ${ }^{5}$ ) dominationi uidebuntur in ea quantitate que uidebitur et eo tempore quo uidebitur.

Die VI. iunii [indic. III. 1350].

71 Cl. f. p. p. Bartholomeum de Bonfilio g. in lobio et extra por-

1) Dieses Dekret, das sich später oft wiederholt, findet sich auch in knapper Redaktion bei Noiret a. 1407 p. 175.

9) Hs: nichilcminus.

3) Scala Strumbuli und scala de Prinangulo; vgl. Xanthudides p. 304.

4) Hs: elligere. $\quad$ 5) Fehlt ein Wort. 
tas, cum ad hoc, ut iuuenes quicunque armis exercitentur pro bono patrie, per dominationem ordinatum sit secundum partem captam in maiori consilio, poni sub conestablariis omnes uiros de ciuitate et burgo Candide de XVI annis supra et de XXXVI infra constituendo capita singulis XII, dominus ducha et eius consilium mandant, quod omnes ipsi uiri de ciuitate et burgo, qui sub dictis conestablariis ponentur, teneantur obedire proprio capiti secundum capitulare quod ei dabitur et debeant per totum presentem mensem iunii recuperasse balistas seu archus et sagittas sub pena ypp. quinque pro quolibet contrafaciente et ex nunc una die ad minus in qualibet ebdomada predicti uiri teneantur ire et esse cum capite sibi deputato ad balistandum seu archandum ita quod pro nobilibus sit ad hoc ordinata dies mercurii et pro omnibus aliis dies domenica, et tunc debeant proicere cum balista seu archu decem ictibus ad minus pro quolibet eorum ita quod hoc sit notum dicto capiti, sub pena cuilibet nobili contrafacienti grossorum trium et cuicunque alii contrafacienti grossorum duorum pro qualibet die qua contrafecerint, et unumquodque constitutum 'caput, sicut dictum est, teneatur similiter ire balistare seu archare modo predicto et sub eadem pena et ultra hoc teneatur etiam sub pena sacrimenti scribere omnes illos sibi deputatos, qui non obseruauerint quod superius continetur et presentare ipsos in scriptis intra tertium diem officialibus deputandis ad hoc per dominium, ut dicte pene integraliter exigantur.

Die XXVIII. iunii indic. III. ad hoc: stridatus fuit dictus ordo et exactio penarum commissa est officialibus de nocte. ${ }^{1}$ )

Die XII. ianuarii [indic. III. 1365].

47 Cl. f. p. p. Iohannem Marino g., quod cum alias factum fuerit bannum, quod omnes qui habuerunt arma comunis tempore rebellionis, deberent ea restituere sub certa pena, et dicta arma non fuerint restituta, dominus ducha et eius consilium iterato faciunt notum omnibus et mandant, quod omnes et singuli qui habuerunt arma comunis, mutuo uel aliter tempore dicte rebellionis, debeant reddere et restituere ipsa arma in manibus comerclarii comunis, amodo usque ad dies VIII proxime uenturos, sub pena dupli ualoris ipsorum armorum, de qua quidem pena accusator...

Die VIII. iulii [indic. VII. 1369].

66 Cl. f. p. p. Nicoletum de Molino g., cum ad aures dominationis peruenerit, quod in banderiis soldatorum Candide equestrium et pedestrium sunt multi uxorati, habentes uxores legitimas oriundas de Can-

1) Dieser Nachsatz ist mit blasser Tinte und kleinerer Schrift hinzugefügt. 
dida uel insula Crete, et dominatio uelit scire qui sunt illi et cuius modi conditionis sint uxores eorum, dominus ducha et eius consilium faciunt notum omnibus et mandant, quod omnes et singuli soldati qui sunt in banderiis equestrium et pedestrium soldatorum Candide, qui sunt uxorati et habent uxores oriundas de Candida uel de insula Crete, conparere debeant coram dominatione amodo usque ad dies IIII proxime uenturos ad manifestandum uxores suas et conditiones earum, et sit notum omnibus, quod quicunque non conparuerit ad dictum terminum, cassabitur de soldo comunis et erit priuatus taliter, quod non poterit esse amplius soldatus in Candida et ultra hoc cadet in penam ypp. V, et si accusator...

Die VIIII. decembris [indic. VIII. 1369].

99 Cl. f. p. p. Iohannem Marino g., quod cum dominatio et dominus capitaneus Crete intendant scire omnes equos, roncinos, mulos et mulas qui sunt in manibus quarumcunque personarum extra uarnitiones feudatorum, dominus ducha et eius consilium et dominus capitaneus antedictus faciunt notum omnibus et mandant, quod omnes et singuli habitantes in ciuitate et burgo Candide et in castris et casalibus atque aliis locis positis in districtu Candide cuiuscunque conditionis existant, qui habent et tenent aliquos equos uel roncinos aut mulos uel mulas ${ }^{1}$ ) in quibuscumque locis extra uarnitiones feudorum, debeant conparere et scribi facere dicta animalia qui ipsi tenent, siue teneant ea suo nomine proprio, siue teneant nomine aliorum quocunque modo uel ingenio, a modo usque per totum mensem decembris presentem, sub pena perdendi illa animalia que non fuerint scripta seu ualorem eorum et ypp. uigintiquinque pro quolibet ipsorum, de quibus quidem penis accusator...

\section{c) Sittenverordnungen.}

Die XIII. mensis ianuarii [indic. XIII. 1330].

XXVI Cl. f. p. p. Petrum Uido g., quod omnes illi qui fecerint nuptias in ciuitate, non possint tenere curiam nisi usque ad horam uesperarum et omnes teneant recedere de ipsis curiis ad dictam horam sub pena illis qui haberent nuptias ypp. quinquaginta et illis qui remanerent sub pena ypp. uigintiquinque pro quolibet, et non possint remanere in cenis ad dictas nuptias, nisi pater et mater, fratres et sorores, sponsi et sponse et germani consanguinei, cognati et cognate et nepotes et neptes filii uel filie fratris et sororis ipsorum sponsi et sponse sub eisdem penis.

1) Hs : mullas. 
XXVII Item in omnibus aliis qui tenerent curias sine nuptiis intelligatur, quod non possint ipsas curias tenere nisi usque ad uesperas sub dictis penis tam illis qui tenerent ipsas curias, quam illis [qui] remanerent ad ipsas curias ultra horam predictam.

XXVIII Regest: Niemand soll in -cenis mehr als vier Personen zu sich einladen, bei einer Strafe von 50 Perpern für den Gastgeber und 25 für die Gäste.

XXVIIII Regest: Der Ankläger soll $1 / 4$ der besagten Geldbuße erhalten, der officialis de nocte $1 / 4$ für die Untersuchung und die Gemeinde den Rest.

Et omnes predicti ordines intelligantur durare usque ad diem primum quadregesime proxime uenture.

Die quarto mensis iunii [indic. VII. 1339] ${ }^{1}$ )

14 Item quia honestum et salutiferum esse dignoscitur, quod pro obuiandis communi danno atque malo et inordinatis expensis et pro conseruatione bono ac utilitate tam feudatorum quam ceterorum habitantium Crete refrenetur libertas quamplurium super indumentis siue uestibus atque ornamentis mulierum ac uirorum in quibus non solum adest uana gloria sed etiam damnum sinistrum et conditio stricta quamplurium, et quod decetero aliqua mulier cuinscunque conditionis existat tam nupta quam domicella non possit habere pro suo usu plus una frisiatura perlarum ualoris ab ypp. LXXX inferius sub pena ypp. $\mathrm{XXV}$ pro qualibet et qualibet uice. Et si accusator inde fuerit seu pueri inuenientes habeant tertium dicte pene, tertium comune et reliquum tertium aduocatores comunis, et si non fuerint accusatores uel pueri diuidatur per medietatem.

15 Item quod non possit uti nec portare super se aliquas perlas exceptis autem drezadoriis quibus sit licitum posse portare qui tamen sint ualoris ab ypp. CC infra sub dicta pena ot modo predicto diuidenda.

16 Item quod non possit uti nec portare aliquam tunicam habentem caudam excepta una sub pena ypp. $X$ pro qualibet et qualibet uice modo predicto diuidenda.

17 Item quod non possit uti nec portare epitogium uel uarnationem que menare possint per terram ultra brachia II panni in cauda, intelligendo pro medietate altiadure anteriorem inferius sub pena ypp. $X$ pro qualibet et qualibet uice modo predicto diuidenda.

18 Item quod aliqua mulier cuiuscunque conditionis existat, non

1) Der Anfang dieser Proclami handelt von Rechtsangelegenheiten und steht deshalb unter Kapitel „Rechtsverhältnisse“. 
possit ponere nec portare ornamentum aliquod in tunica sua, çuba seu duppleto per furnimentum ultra ualorem ypp. IIII uidelicet in asolis, frisiis uel lotonis, nec possit pomere in aliquo suo uarnimento dopplonos aureos ualoris ultra grossas; IIII pro bralno sub pena ypp. $X$ pro qualibet et qualibet uice, modo predicto diuidenda.

19 Item quod non possit ponere nec portare in suo epitogio uarnacia uel altero suo uarnimentto frisiaturam aurei uel asolis nisi a ualore ypp. XX inferius sub pesna ypp. $\mathrm{X}$ pro qualibet contrafaciente et qualibet uice, modo predicto diuidenda.

20 Item quod aliquis infanss tam masculus quam etiam femina ab annis $\mathrm{X}$ infra non possit portare super se aliquas perlas nec hauere etiam in aliquo suo uarnimento intra aurum, argentum seu aliquod aliud suum ornamentum ultra ualorem ypp. duorum. Nam postquam expleuerint dictam etatem annorum $X$, sint tunc ad esse et conditionem aliarum, exceptando autem in hoc et excludendo inforaturam uidelicet pellem accendatam, sub pena y'pp. X pro quolibet contrafaciente et qualibet uice, quam quidem penam soluant patres eorum uel sui maiores modo predicto diuidendar.

21 Item quod nullus uir cuiuscunque etatis existat, possit portare uestimentum aliquod de uelluto, uel de samite(?), uel etiam pannum aliquem ad aurum, nec hauere etiam super aliquibus suis uestibus perlas, aurum uel argentum nec frisios seu cordellas aureas uel argenteas, sed solum sit licitum posse portare perolos seu bospilos argenteos uel superauratos tantum in caucecio uel in manichis eorum sub pena ypp. XXV pro quolibet uarnimesnto et qualibet uice, dicto modo diuidenda.

22 Item quod aliquis uir cuiuscunque conditionis existat, ab annis XXX inferius, non possit habere pro suo usu plus duobus uarnimentis inuarotatis sub pena ypp. $X$ pro quolibet contrafaciente dicto modo diuidenda.

23 Item quod pro moderando multa que fiunt in nuptiis inordinate ad aliquas nuptias, que fientt de cetero, non possit uel debeat fieri aliquod conuiuium tam uirorum quam mulierum, tam ex parte sponsi quam etiam sponse per mensem unum ante transductionem sponse et per unum mensem post, saluo in die nuptiarum, in quo non possint interesse ad comedendum uiri alicqui, non intelligendo de iuuenibus qui forent pro seruiendo in ipsis nupitiis non entibus suprascriptis ultra $X$, secundum tamen dominas que nom possint esse inter omnes tam domicellas quam maritatas et intra utramque partem scilicet tam sponsi quam sponse ultra LXXX.

24 Et quod ad nuptias ipssas non possit nec debeat comedere 
aliqua sclaua ancilla uel pedisequa aut famula modo aliquo et non possit amodo per sponsum uel nomine sponsi per VIII dies ante diem nuptiarum et VIII post mitti aliquid pro presente extra domum nec etiam in die nuptiarum. Et qui contrafaciet in predictis uel singulis predictorum tam sponsus quam sponsa uel alius contrafaciens cadat in penam ypp. $V$ pro quolibet et qualibet uice.

25 Item quod decetero nulla persona audeat ante solis ortum uel post solis occasum ludere ad aliquem ludem taxilorum ad quem uadant denarii in domo aliqua uel statione uel in aliquo alio loco occulto preter quam in platea et sub lobio sub pena ypp. XXV pro quolibet sic ludente et qualibet uice et restituendi seu reddendi totum illud quod fuerit lucratum cui id fuerit lucratum, et sub pena illi in domo cuius uel statione luderetur ypp. C pro qualibet uice dicto modo diuidenda.

Die XVIII. mensis iunii [indic. VII. 1339].

26 Cl. f. p. p. Georgium Cornario g., quod per ordines pridie captos et stridatos in facto uestium et ornamentorum personarum Crete mulieres dubitant et nesciunt quomodo debeant uiuere in hoc passu, quod concessum sit omnibus grecis mulieribus et iudeis, quod ipse possint ferre pro suis ornatibus de capite et dorso in perlis et argento et auro ad suum morem usque ad illam summam et quantitatem precii usque ad quam concessum est latinis dominabus.

Die XVII. marci [indic. X. 1356].

89 Cl. f. p. p. Iohannem Marino g., quod cum Katarina tabernaria ser Iacobi Pantalio, habitator[is] burgi Candide, conparuerit coram dominatione cum quadam infantula paruula, asserens, quod sunt dies III quod ipsam dictam infantulam que uocatur Christina inuenerit proiectam ante ianuam ecclesie sancti Marci et ipsam anore dei accepit. Quare suplicauit ut clamare mandaretur, quod quicumque haberet ad dicendum aliquid de ipsa infantula conpareret, ne futuris temporibus sibi questio aliqua moueretur, dominus ducha et eius consilium mandant, quod si est aliquis qui uellet petere dictam infantulam aut pro herede aut pro sclaua aut pro uillana, aut quocunque alio iure, conparere debeat hinc ad mensem unum proximum coram dominatione, ad satis faciendum sibi suas expensas et accipiendum illam, quia dominatio de hoc faciet, prout ius postula[bit] et sibi uidebitur expedire, aliquin ab inde in antea ipsa infantula erit libera, tamquam filia adoptata suprascripte Katarine.

Die VIIII. maii [indic. III. 1365].

64 Cl. f. p. p. Nicolaum de Molino g., quod decetero non debeat 
sepeliri ${ }^{1}$ ) aliquod funus in aliqua ecclesia seu loco positis in ciuitate Candide sub pena ypp. XXV pro quolibet funere, in quo fuerit contrafactum, quam quidem penam incurrere debeat ille propinquus defuncti, qui eum fecerit sepeliri ${ }^{1}$ ), et similem penam incurrat patronus ecclesie, si eclesia, in qua illud funus fuerit sepultum, erit grecorum, exceptis tamen illis, qui habent suas archas proprias, quibus sit licitum sepeliri ${ }^{1}$ ) in ipsis suis archis.

Item quod decetero in funeribus puerorum marium uel feminarum habentium ab annis XII infra non debeant ire ultra personas IIII intra masculos et feminas, que ipsa corpora portabuntur ad sepulturam sub pena ypp. X pro qualibet persona contrafaciente et qualibet uice, exceptis tamen clericis, sacerdotibus et religiosis qui ibunt ad dictum funus.

Der Leichenzug soll nicht mehr durch die ruga maestra, sondern durch Nebenstraßen ziehn.

Item quod nulla persona audeat decetero cantare in ciuitate ad aliquem mortuum uel mortuam uel occasione alicuius mortui uel mortue sub pena standi in carcere per dies XV et perdendi ypp. $\mathrm{V}$ pro qualibet uice qua contrafecerit, et quod aliqua persona non permittat ipsos cantare in domo sua sub pena $\mathrm{ypp} . \mathrm{X}$ pro qualibet uice qua fuerit contrafactum.

Et predicta committantur dominis de nocte, aduocatoribus comunis et iusticiariis qui inquirant de predictis et a contrafacientibus exigant dictas penas, de quibus accusatur.....

Die XVIIII mensis iunii [indic. VI. 1338].

Cl. f. p. p. Georgium Cornario g., quod Paganinus Leno non debeat in aliquo suo loco uel domo tenere bordellum uel proscribulum sub pena ypp. quinque, et quod ipse non debeat aliquam mulierem recipere uel receptare in loco suo aliquo uel domo pro faciendo uel committendo adulterium sub pena ypp. quinque pro qualibet muliere quam sic receptauerit et qualibet uice, quarum penarum domini de nocte habeant tertium et comune duas partes. Et si accusator .....

Die XXII. iulii [1369].

72 Cl. f. p. in lobio et extra portas ciuitatis Candide per Iohannem Marino g., quod cum alias factum fuerit bannum inferius annotatum, iterato dominatio facit eum renouari, cuius tenor talis est: Quia ualde iniquum et abominabile reputatur, ut quis duas uxores habere temptet, quod aliquando commissum est hactenus per homines non timentes deum et de uerecondia seculi non curantes, dominus ducha et

1) Hs: sepelliri. 
eius consilium ad correctionem huius uicii mandant, quod quicunque deinceps desponsauerit duas uxores, teneatur restituere secunde quam desponsauerit, repromissam quam ab ea receperit in duplum, et etiam incurrat penam ypp. quinquaginta, et si non haberet ad soluendum comuni dictam penam de ypp. quinquaginta, quod propterea stare debeat in carcere menses sex, nihilominus debeat sufferre maiorem uel minorem penam tam de pecunia quam de carcere, seu aliter secundum qualitatem excessus et conditionem personarum, prout dominationi uidebitur dare penam.

\section{Erlasse für die Berufsklassen.}

Aus unsern Proclami, auf die wir für dieses Kapitel allein hingewiesen sind, läBt sich nicht mit Sicherheit eine organisierte Werkgenossenschaft für Kreta nachweisen, doch ergibt sich aus dem vorliegenden Material immerhin, daB die wichtigsten Berufsklasșen, wie die Wirte, Fleischer, Schmiede, Goldschmiede, Schuster usw., durch zum Teil rigorose, geschlossene Korporationen voraussetzende Vorschriften administriert wurden. Wir erhalten aus Untenstehendem erwünschte Auskunft über den Verkauf von Käse, Salz, Brot, Fleisch, Fischen, Öl, Kohlen, Wolle, Waffen, und detaillierte Vorschriften für die Schmiede und Goldschmiede geben uns ein annähernd deutliches Bild der zwei wichtigsten mittelalterlichen Berufsklassen.

Wie in Venedig, wurden auch in Kreta der Verkauf von Getreide, Käse und Salz, die Miete der MaBe für feste und flüssige Körper, die Sensalgeschäfte ${ }^{1}$ ) verpachtet. Es war dies ein System, das in allen monopolisierenden Staaten zu jeder Zeit den Schmuggel und andere Betrügereien erzeugen half. Invalide und ausgediente Matrosen bekleideten seit 1416 das Amt der Wäger und Abschätzer, Getreide- und Mehlmesser, die drei iustitiarii überwachten die Fleisch- und Fruchtpreise und kontrollierten die MaBe und Gewichte. ${ }^{2}$ )

Wenn in Venedig die Bäcker die Korporation der Pistori bildeten, sind in Kreta und anderswo, z. B. in $\mathrm{Grado}^{3}$ ), die Wirte (pancogoli) vom Staat autorisiert, das Brot zu verkaufen. In Venedig kam eben zur Brotbäckerei noch die ausgedehnte Fabrikation von Schiffszwieback hinzu, die einen Beruf voll und ganz ausfüllen mochte.

Für die Grob- und Feinschmiede existierten viel eingehendere Bestimmungen als heutzutage; waren doch der tägliche Arbeiterlohn, der

1) Für das Jahr 1442 wurde das datium missetarie an Georgius Dandulo von Kreta um 14600 Perpern verkauft, wobei dieser aber zu Schaden kam. Noiret p. 411.

2) Vgl. auch Gerland, Archiv p. 63, und Noiret p. 247.

3) Nach Caprins schönem Werk "le lagune di Grado". 
Preis für den Hufbeschlag, für das Eisen und die Nägel festgesetzt und die Goldschmiede außerdem gehalten, auf ihren Waren den Legierungsstempel aufzuprägen, ein Doppel desselben auf der Kanzlei zu deponieren und alljährlich bei Gefährdung ihrer Existenz ein Ehrlichkeitsgelübde abzulegen. Damaliger Sitte gemäß waren ihre Magazine, wie die der Goldschmiede von Florenz auf dem Ponte vecchio, auf der Plathea vereinigt.

a) Verkauf von Käse.

Die XIII. maii [1314].

45 Cl. f. p. p. Bartholomeum g., quod nulla persona de cetero audeat ponderare uel ponderari facere caseum de magaçeno, si extimatores qui sunt ordinati per signoriam, non fuerint presentes in ipsis ponderibus qui extimabunt ipsum caseum pro sale et inmundiciis aliis que ponuntur per uenditores super ipso caseo magaceni; qui extimatores habere debeant pro quolibet miliario casei tornensem unum tam ab emptore quam a uenditore, sciendo, quod qui contrafaciet, ut dictum est, cadet in penam ypp. uigintiquinque pro quolibet contrafaciente pro qualibet uice, de quibus accusator ...

\section{b) Verkauf von Salz.}

Die III. nouembris [indic. VIIII. 1370].

16 Cl. f. p. p. Iohannem Marino g., quod cum secundum formam ordinum olim factorum sit prohibitum, quod nulla persona cuiuscunque conditionis existat, possit uti ullo modo uel ingenio pro usu domus et familie sue, uel pro aliquo alio exercitio intra et extra aliquo alio sale, preterquam de sale comunis daciato, et in hoc multe fraudes committantur in dannum comunis, specialiter in facto casei qui per mercatores et alias personas incinnipatur et salitur de alio sale accepto furtiue et non de sale comunis daciato, dominus ducha et eius consilium uolentes huiusmodi fraudibus obuiare, faciunt notum omnibus et mandant, quod decetero quicunque habuerit caseum in aliqua quantitate magna uel parua, et illum tenebit uel conseruabit in domo uel magaçeno aliquo in ciuitate uel burgo Candide seu in aliis ciuitatibus et castris insule Crete aut in burgis eorum uel in aliquibus casalibus, non possit salire uel saliri facere dictum caseum cum aliquo alio sale, preterquam de sale comunis daciato sub pena perdendi totum ipsum caseum, de quo fuerit contrafactum, et ne aliquis possit se excusare, dicens fictiue seu fraudulenter se saliuisse caseum suum de sale empto ab officialibus deputatis [ad] uendendum salem comunis, statutum et ordinatum est, quod decetero omues et singuli officiales deputati ad uen- 
dendum salem comunis in singulis ciuitatibus et castris insule teneantur scribere die qualibet totum salem quem uendiderint unicuique persone a mensuris duabus supra, scribendo nomina personarum ementium ipsum salem et diem et quantitatem que fuerit eis uendita, ut in omni casu, qui posset occurrere, pateant omni tempore nomina personarum ementium dictum salem comunis, et tempus quo illum emerint, et quantitates que fuerint eis date. Remanentibus nihilominus firmis, omnibus aliis ordinibus, ligaminibus et stricturis factis usque modo de sale, cum penis contentis in eis . . Et predicti committantur in Candida comerclariis comunis, qui teneantur inquirere de predictis et a contrafacientibus...

Item anno domini MCCCLXXI mense maii die XIII. indic. VIIII. per dominationem ordinatum est, quod predicta omnia committantur etiam dominis de nocte modo predicto.

c) Verkauf von Brot.

Die X. mensis aug. ${ }^{\mathrm{i}}$ [indic. III. 1320].

$47 \mathrm{Cl}$. f. p. p. Riçardum g., quod nulla persons audeat a die mercurii proxime uenturi in antea facere panem ad uendendum nisi pancogoli qui ordinabuntur per signoriam sub pena ypp. $V$ pro quolibet et qualibet uice, et ipsi pancogoli ordinandi non audeant facere panem de alio frumento quam de illo quod eis dabitur per signoriam sub pena perdendi ipsum panem quem facerent de alio frumento et tantundem de suo quantum ualeat dictus panis quem facerent de alio frumento, de quibus penis accusatores ... .

Et omnes pancogoli qui uolunt facere panem ad uendendum de dicto frumento comunis cum dictis conditionibus, debeant uenire ad faciendum se scribi.

Die II. aprilis [indic. X. 1320].

19 Cl. f. p. p. Petrum Uido g., quod nullus audeat decetero facere panem ad uendendum minoris ponderis unciarum VIII sub pena perdendi panem qui reperiretur minoris ponderis et unius sterlini pro quolibet pane qui ponderaret minus unciis VIII.

Die XVIII. iunii [indic. VIIII. 1371].

62 Cl. f. p. in lobio et extra portas ciuitatis Candide in loco solito per Iohannem Gradonico g., quod quicunque uoluerit facere panem ad uendendum, debeat infra tertium diem proximum conparere coram comerclariis comunis et facere se scribi et accipere de frumento comunis, quod est frumentum de Creta, tantum quantum fuerit ei datum ab ipsis comerclariis. Et quicunque acceperit de frumento comunis, possit uendere panem factum de ipso frumento et de quolibet alio 
frumento, ita tamen, quod panis dandus pro uno tornesello sit ponderis unciarum nouem, et sit bene coctus et bene saponatus. Et quod nullus alius audeat uendere panem nisi illi qui habuerint de frumento comunis, et si quis contrafecerit ...

Die sabati uigesimo septimo septembris.

71 [Regest] Es dürfen bei Strafe nur noch panes bullati bulla comunis verkauft werden.

\section{d) Verkauf von Fleisch.}

Die XXV. aprilis [indic. XI. 1342].

90 Cl. f. p. p. Lecarinum Rosso g. in lobio [et] extra portas ciuitatis, in macello seu beccaria christianorum et Iudeorum, quod omnes beccarii tam christiani quam iudei qui decetero emerint aliquas bestias tam grossas quam minutas, teneantur scribi facere in camera iusticiariorum per scribas iustitie absque aliqua solutione, in quo casali et loco et a quo uillano uel persona emerint et quantitatem bestiarum et signa eorum et diem et tempus sub pena ypp. V . .

Die XV. mense nouembris [indic. XIIII. 1360].

32 Cl. f. p. p. Bartholomeum de Bonfilio g. in lobio et extra portas ciuitatis Candide, cum macellum Candide male fulciatur carnibus et multi conquerantur, quod non possunt habere carnes de macello, quod omnes carnes de macello cuiuscunque maneriei sint, uendantur ad pondus hiis preciis uidelicet, quod carnes castrine intelligendo carnes hirci castrati non possint uendi ultra perperos XII pro qualibet libra ....1) Item carnes bouine tam iuuenum quam ueterum bouum uendantur prout fuerint exstimate a iusticiariis uel a scribis eorum, quando iusticiarii non poterunt ire ad macellum.

Item cum plures persones sint solite uendere carnes porcinas prope ecclesiam sancte Marie de macello ad earum arbitrium, de cetero nulla persona audeat uendere huiusmodi carnes porcinas in dicto loco, nisi ad pondus preciis suprascriptis, et non possint uendere dictas carnes nisi post ecclesiam antedictam, non intelligendo in hiis ordinibus persuta et spacullas, et ut melius et iustius ualeant ponderari quilibet nacellator et uenditor carnium predictarum, habeat unam bellanciam et unam stateram et omnia pondera ad hec necessaria ita tamen, quod cum bellancia debeant ponderari usque ad octo libras et inde superius possint ponderari cum statera, facientes bonum et iustum pondus ... ${ }^{2}$ )

Item quod officio iustitie addantur duo famuli ad hec ut predicti

1) Ich übergehe 4 Abschnitte.

2) Dann folgen die Straf bestimmungen. 
ordines possint melius adimpleri, ita quod unus ad unum dictorum famulorum ad muduam deputetur in loco consueto prope becariam, ubi debeat figi unus scillus, ut ipse famulus ibi reuideat et reponderet carnes emptas, et si inuenerit aliquod falsum, debeat illud cito iusticiariis denotare. Et ipsi procedant prout fuerit iustum, qui pueri habeant salarium et lucrum consuetum sicut alii pueri . . . .1)

Item quod predicti ordines nullomodo extendantur ad regalias dominationis et durent dicti ordines ad eius beneplacitum et mandatum.

e) Verkauf von Meerfischen.

Die IIII. nouembris [1338].

58 [Regest] Niemand darf mehr uendere pisces salitos in ciuitate uel in aliqua alia parte posita quam in banchis siue scamnis stabilitis per dominationem extra portas civitatis bei einer BuBe von $10 \mathrm{ypp}$.

\section{f) Verkauf von öl.}

Die XVIIII. decembris [indic. IIII. 1350].

$10 \mathrm{Cl}$. f. p. p. Iohannem Marino g. in lobio et extra portas, quod nemo audeat uendere oleum in grosso sine licentia expressa dominii que scribatur in curia sub pena quarti pro qualibet uice, de qua pena accusator ...

Item quod nemo audeat uendere oleum ad minutum sine licentia iustitiariorum, et quicunque haberent dictam licentiam, faciant se scribi ad officium ipsorum iustitiariorum sub pena ypp. duorum pro quolibet contrafaciente et qualibet uice.

Item uendendo oleum ad minutum nemo possit uendere ultra duas libras pro qualibet persona emente in die sub pena quarti pro qualibet uice.

Item quod nemo possit uendere oleum ad minutum ut dictum est supra nisi ad rationem denariorum quadraginta paruorum pro qualibet libra et inde infra sub pena ypp. unius pro qualibet uice.

Item quicunque foret scriptus ad officium iusticiariorum pro uendendo oleum ad minutum et non uendiderit et dederit si habuerit, incurrat penam ypp. unius pro qualibet uice.

Item uendendo oleum ad minutum, non possit aliquis uendere seu dare alicui candelam, acum, coclear aut aliquid aliud cuiuscunque conditionis existat similiter cum ipsa uenditione olei modo aliquo uel ingenio, sed mercatum dicti olei a mercato cuiuscunque alius rei facere debeat separatim et diversis temporibus, ut fraudibus obuietur uenden-

1) Ich übergehe 3 weitere Bestimmungen. 
tium oleum carius quam debeant sub palliatione uenditionis alterius rei, que quidem palliatio nulli ualeat si reperiretur contrafecisse, sed soluere debeat unusquisque contrafaciens penam ypp. duorum pro qualibet uice, de quibus quidem penis . . .

g) Verkauf von Leguminosen, Seide, Wachs, Baumwolle usw.

Die II. septembris [indic. VIII. 1369].

80 Cl. f. p. p. Nicoletum Demolino g. in lobio et extra portas ciuitatis Candide, quod nullus speciarius aut mercarius audeat ponderare in domo uel statione sua siue in aliquo loco preter quam in statera comunis granam, setam, ceram, gotonum, linum aut aliquas alias res, que uendantur per alios sub pena perdendi rem que ponderata fuerit seu ualorem eius et duplum datium.

Item quod quicunque emerit carbones in burgo, teneatur presentare daciario porte uenditorem ipsorum carbonum, ea die qua emerit carbones ut soluat datium dicte porte, sub pena perdendi dictos carbones seu ualorem eorum et duplum datium.

Item quod inponatur illis qui tenent ad affictum mensuras et miscata comunis, quod quotiescunque dederint alicui persone mensuras seu miscata ad mensurandum extra plateam aliquos fructus seu aliquam aliam rem, pro qua soluatur datium porte, teneantur statim ea die qua dicte res mensurate fuerint notificare daciario porte quantitatem et ualorem illorum que mensurate fuerint et nomina personarum uendentium eas, ut possit excutere id, quod sibi debetur pro datio dicte porte, sub pena gross. unius pro qualibet mensura seu miscato rerum, que fuerint mensurate. Et de penis predictis accusator ...

\section{h) Verkauf von Wolle.}

Die XIII. maii [1332].

46 . . Item cum per multos ematur lana sub statera, que lana fertur per mare et per terram, quam lanam emptores mittunt in suos magacenos et ex ipsa extrahunt florem et subtilem lanam; propterea quod residuum lane est multum peius, si aliqua persona deinceps extrahet de ipsa lana florem et lanam subtilem et reliquum noluerit uendere, quod uenditor teneatur id dicere et manifestare emptori, quod extraxerit de lana de melioramento, ad hoc ut emptor non sit deceptus et quod sit prouisus de ipsa lana, sciendo, quod qui contrafaciet, cadet in penam ypp. uigintiquinque pro qualibet uice, de quibus accusator habeie deleat medietatem . . .

Isti sunt extimatores ordinati per signoriam: Dimitrellus Messetta, 
Xennus Messetta, unus ex ponderatoribus, scilicet ille qui erit ad pondus. Iurauerunt de officio legaliter exercendo.')

\section{i) Verkauf ron Pfeil und Bogen.}

Die XVIIII maii [1332].

59 Cl. f. p. p. Petrum Uido g., quod omnes ille persone que uolent emere arcus uel sagittas, si non potuerunt esse concordes de pretio cum magistris a quibus uoluerint emere dictos arcus et sagittas, debeant redire ad nobiles uiros Laurentium Secreto, Uictorem Taiapetra et $\mathrm{Phi}$ lippum Cornario qui constituti sunt per signoriam super hoc, ad taxandum pretium eorum sicut eis videbitur iustum. Et magistri teneantur stare extimationi dictorum sapientium sub pena ypp. duorum pro quolibet et qualibet uice.

\section{k) Vom Beruf der Schmiede.}

Die XII. marcii [indic. IIII. 1351].

21 Cl. f. p. in lobio et extra portas ciuitatis Candide per ambos gastaldiones, dominus ducha dat intelligi, quod cum sint nuper facti certi ordines per consilium rogatorum, confirmati postmodum in maiori consilio super seruiciis et solutione artificum et operariorum, dominus ducha et eius consilium mandant uniuersis et singulis, quod dictos ordines debeant inuiolabiliter obseruare secundum modum et formam contentorum in ipsis et sub pena, de quibus in eis fit mentio; quorum quidem ordinum tenor talis est:

Quod quilibet magister faber caput stationis exercens artem suam, cum dicatur fore $\mathrm{X}$ stationes fabrorum inter ciuitatem et burgum Candide, teneatur qualibet ebdomada infalibiliter presentare et dare uni persone ad hoc per dominium deputande XXV ferra ab equis, mulis et saumeriis laborata eorum propris manibus, uidelicet VIII pro sonipedibus, XII pro ronciniis et quinque pro mulis ${ }^{2}$ ) et saumeriis, et clauos CCL, que ferra et claui sint bona et mercabilia, non accipientes a dicta persona pro solutione dictorum ferrorum et clauorum ultra solutiones inscriptas, uidelicet pro quolibet ferro a sonipede tornenses VIII. Item pro quolibet ferro a runcino et anillo tornenses VI et pro quolibet ferro a saumeriis turonenses III et pro quolibet C clauorum soldinos VI sub pena ypp. duorum pro quolibet contrafaciente et qualibet uice, diuidenda intra camerarios comunis, officiales de nocte, aduocatores comunis et iustitiarios, quibus hoc committatur ${ }^{3}$ ), uidelicet illos de predictis, qui prius intromiserint et repererint excessum et accusationem,
1) Randbemerkung.
2) Hs: mullis.
3) $\mathrm{Hs}$ : comittatur. 
et comune per tertium. Et nihilominus huiusmodi faber teneatur supplere suum defectum ${ }^{1}$ ), dicta uero persona per dominium ad hoc deputanda teneatur indeficienter uendere uel uendi facere per suum proprium missum super platea Candide dicta ferra et clauos non accipiendo pro sua prouisione et labore ab emptoribus plus uno denario paruo pro quolibet ferro uendendo per eum ultra id quo sibi constiterit et de quolibet $\mathrm{C}$ clauorum uendendorum per eum non accipiendo plures duobus paruis ultra id quo sibi constiterit iuxta precia suprascripta ueruntamen ab ementibus ... ${ }^{2}$ ) duobus paruis $L$ clauis possit dicta persona accipere etiam unum denarium paruum ultra id quo sibi constiterit, teneatur insuper persona predicta per sacramentum denunciare predictis officialibus omnes fabros qui contrafecerint et qualibet uice, quod si non fecerit, incurrat illa persona penam similem.

Item nullus inferator possit accipere pro sua solutione pro quolibet pede sonipedis quem inferrabit cum suo ferro et clauis ultra solidos ${ }^{3}$ ) III.

Item pro quolibet pedum runcini, mulit) et mule quem inferrabit cum ferro et clauis suis non possit $^{5}$ ) accipere ultra solidos II.

Item pro quolibet pede saumerii inferrando cum ferro et clauis inferatoris non possit accipere ultra solidos II . . . $)$

Item pro quolibet remittere cuiuslibet pedum runcini, muli et mule cum clauis inferratoris et ferro patroni animalis non possit inferrator accipere ultra tornenses $\mathrm{V} \ldots .^{7}$ )

Et teneantur omnes inferratores inferrare et remittere omnia huiusmodi animalia pro quibus fuerint requisiti, non transgredientes pretia et solutiones predictas, non recusando nec $\ldots{ }^{8}$ ) huiusmodi seruitium alicuius persone.

Item quod nullus cerpitoris, çapatoris, catauoliçatoris, lachiçatoris, messoris, manipuloris operariorum et cudoris ferri ad cudinem audeat accipere pro premio seu laboris pro quolibet qualibet dieta integra qua laborauerit ultra solidos ${ }^{9}$ ) sex, tamen sit licitum illis qui facient fieri huiusmodi seruitia dare ad bilendum suprascriptis laboratoribus si uoluerint, sed pro sua commestione nil habere possint $\ldots{ }^{10}$ )

1) Hs: deffectum.

2) Ein Wort unleserlich.

3) Hs: solidum.

4) Hs: mulli et mulle durch die ganze Urkunde.

5) Hs: posit.

6) Ich übergehe zwei ähnliche Bestimmungen.

7) Ebenso.

8) Fehlt ein Wort.

9) Hs: solidum.

10) Es folgen noch 33 kurz gehaltene Bestimmungen. 
l) Verkauf des Eisens.

Die VII. octubris [indic. VIIII. 1370].

18 Cl. f. p. p. suprascriptum g. ${ }^{1}$, cum in datiis impositis ferro laborato et non laborato contineatur, quod quicunque emerit ferrum pro laborando uel extrahendo illud, soluere debeat ypp. duo pro quolibet milliario librarum, et hoc datium multimodo defraudetur in dannum comunis, dominus ducha et eius consilium uolentes huiusmodi fraudibus obuiare, faciunt notum omnibus et mandant, quod omnes obseruari debeant ordines inferius annotatos:

Primo quod omnes merçarii et alii uendentes ferrum ad minutum debeant conparere coram comerclariis et facere scribi totum ferrum laboratum et non laboratum, quod habent in stationibus et magacenis suis amodo usque ad dies tres proximos sub pena perdendi totum illud ferrum, de quo fuerit contrafactum.

Item quod decetero nulla persona cuiuscunque conditionis existat, audeat uendere ferrum non laboratum ad minutum scilicet ad pondus, et debeat ponderare iuste et legaliter omnes et singulas petias ferri, quas ipse uendiderit quibuscunque personis sub pena ypp. quinque et perdendi ferrum, de quo fuerit contrafactum pro qualibet uice, qua fuerit contrafactum, et sit notum omnibus quod ordinatum est, quod in porta platee ponatur et teneatur continue una statera, in qua quelibet persona poterit ponderare ferrum quod sibi fuerit uenditum et uidere, si fuerit iuste ponderatum nec ne, et si in ponderis ipsius inuenietur aliqua fraus, obseruabitur presens ordo contra illum qui culpabilis fuerit.

Item quod totum ferrum non laboratum, quod repertum fuerit in manibus quorumcunque merçariorum et aliorum uendentium ad minutum, bullari debeat et ponatur bulla in singulis uirgis dicti ferri, et hoc fiat per comerclarios antedictos, uidelicet de illo ferro, quod presentialiter reperitur in manibus eorum.

Item quod uenditores ferri quod uenditur ad minutum, teneantur soluere datium de toto ferro, quod ipsi uendiderint quibuscunque personis, ad rationem ypp. duorum pro quolibet milliario librarum comerclariis in fine cuiuslibet mensis et exprimere eis distincte et separate illud quod uenditum fuerit pro extrahendo illud extra ciuitatem et burgum, et separate et distincte totum illud aliud ferrum quod emptum fuerit pro laborando illud in ciuitate et burgo ..2), ut comerclarii sciant summam uniuscuiusque quantitatis distincte et separate. Et pecunia que habebitur de ipso datio ponatur in una capsa que habeat duo
1) Iohannem Marino.
2) Ein Wort unleserlich 
foramina, et ponatur unaqueque ratio separate, uidelicet datium ferri laborandi in ciuitate uel burgo ponatur in uno foramine et hoc retineatur in comuni; datium uero ferri portandi extra ciuitatem et burgum ponatur in altero foramine et hoc detur datiariis, qui habuerunt anno presenti ad affictum datium porte terre, tamen licitum sit suprascriptis uenditoribus, excutere dicta datia ab emptoribus dicti ferri, si non possint ullo modo accipere uel excutere ab ipsis emptoribus nisi tantum quantum solui debet secundum impositionem predictam sub pena gross. unius pro quolibet tornesello quem acciperent ultra datium stabilitum.

Et hec omnia committantur comerclariis ...

m) Vom Beruf der Goldschmiede.

Die XX. septembris [indic. XIIII. 1360].

14 Cl. f. p. in lobio per Bartholomeum de Bonfilio g., quod nullus aurifex audeat facere aliquod laborerium de auro uel argento minus bonum quam de liga sub pena ypp. decem pro quolibet contrafaciente et qualibet uice, nihilominus iusticiarii reperientes huiusmodi laborerium debeant facere illud infondi.

Item quod omnes et singuli aurifices teneantur statim cum conpleuerint aliquod laborerium argenti presentare illud laborerium in manibus illorum trium iuratorum qui ad hoc fuerint per dominium deputati, qui quidem iurati uel maior pars eorum debeant illud laborerium bene considerare et si ipsum cognouerint esse de argento minus bono quam de liga, debeant sine mora presentare illud iusticiariis, ut de ipso exerceant officium suum, sed si ipsum repererint de bono argento de liga, debeant illud bollare bulla ${ }^{1}$ ) comunis que dictis iuratis fuerit consignata et accipiant pro suo labore a dictis aurificibus unum turnensem pro qualibet uncia de argento quod bullauerint ${ }^{2}$ ), et postea illud laborerium, aut sit album aut sit deaureatum debeat, ille aurifex qui illud fecerit, statim bullare sua bulla uel signo speciali, ita quod appareat, ut omni tempore possit illud taliter laborerium cognosci, quis illud fecerit. Et teneantur omnes aurifices dare iusticiariis formam suarum bullarum uel signorum, ut in quaterno notentur, non intelligendo in hoc ordine botonos et alia laboreria que non possunt bullari, tamen subiaceant antedicto ordini quod sint de bono argento de liga. Et ut dicti aurifices diligentius obseruent ea que tenentur, debeant iurare semel in anno per quemlibet mensem septembris de exercendo fideliter artem suam, sub pena Ipp. decem pro quolibet contrafaciente et qua-

1) Hs: bolare bula; so immer in dieser Urkunde.

2) Hs: bulauerint. 
libet uice; et ultra hoc ille, qui recusabit iurare, cassetur arte sua et quicunque aurificum non presentauerit dictis iuratis quodlibet suum laborerium, statim cum illud expleuerit, neque illud bullauerit ut prefertur, incurrat penam ypp. uigintiquinque pro quolibet contrafaciente et qualibet uice.

16 Item quod nullus aurifex audeat mittere aliquem puerum per ciuitatem et burgum, sicut solent mittere causa emendi argentum duplonum et alia spectantia ad artem artificum sub pena ypp. quinque pro quolibet aurifice contraficiente et qualibet uice, et dictus puer fustigetur.

17 Item quod nullus aurifex audeat emere aurum uel argentum in domo uel in aliquo alio loco nisi in statione sua super platea comunis sub pena ypp. quinque pro quolibet contrafaciente et qualibet uice.

18 Item quod nullus aurifex audeat laborare seu exercere artem suam alibi, quam in stationibus comunis, et si dicte stationes non erunt sufficientes dictis aurificibus ad laborandum, illi qui non possunt habere seu laborare in stationibus comunis, debeant exercere et laborare artem suam in stationibus platee comunis et non alibi, sub pena ypp. uigintiquinque pro quolibet contrafaciente et qualibet uice. Et predicti ordines committantur iusticiariis ut inquirant de contrafacientibus ita tamen, quod predicti ordines non preiudicent ordinibus officialium de nocte, et de penis suprascriptis, si accusator fuerit . . .

\section{n) Von den Staatsbeamten.}

Die XIIII. iunii [indic. XIII. 1346].

3 Cl. f. p. p. Lecarinum Rosso g. in lobio, extra portas ciuitatis et in portu Candide, quod dominus ducha et eius consilium faciunt notum, quod ordinatum est per eos, quod quolibet die ...1) ad ortum solis tintinabulum grande sancti Marci pulsetur ad maranguonam et mandat dominatio quibuscunque debentibus laborarie comuni uel specialibus personis, quod ad sonum predictum teneantur esse in laboreriis antedictis.

Item quod dicta campana pulsetur quolibet die ad tertiam, que tertia sit pro omnibus officialibus, nec alia campana pulsetur ad tertiam pro aliquo officio, et sciant uniuersi et singuli, quod iudices et officiales auditis placitis terminatis statim procedent ad audienda et diffinienda placita per precepta non faciendo sonari aliud tintinabulum, non sententiando tamen aliquem reum absentem nisi post dictum sonum tertie.

1) $Z$ wei Wörter unleserlich. 
Item quod dicta campana pulsetur quolibet die ad uesperas, que uespere sint pro omnibus officialibus, nec alia campana pulsetur ad uespros (sic) pro aliquo officio, et sciant universi et singuli, quod iudices et officiales auditis placitis terminatis statim procedent ad audienda et diffinienda placita per precepta non faciendo sonari aliud tintinabulum, non sententiando aliquem reum absentem nisi post dictas uesperas.

Item quod campana predicta pulsetur de nocte ad tertium sonum seu longam, quando debebunt claudi ianue ciuitatis sicut pulsabatur campana palatii, que quidem campana palatii non pulsabitur ad ipsum tertium sonum.

Die XVIII. iunii [1357].

102 Preconieatum fuit p. p. Bartholomeum de Bonfilio ministerialem, quod omnes debentes dare comuni denarios pro affictibus casalium, terrarum et domorum dicti comunis, debeant soluisse in camera totum id, quod dare debent amodo usque ad diem domenicum proximum XXV mensis presentis iunii, alioquin, ellapso dicto termino, dominatio poni faciet ad incantum terras et domos pro quibus dari debebit dictus affictus et faciet eas uendi et deliberari plus ${ }^{1}$ ) dare uolentibus omn[i] occasione ac dilatione ${ }^{2}$ ) remota.

Bern.

Dr. J. Jegerlehner.

$\begin{array}{ll}\text { 1) Auf Rasur. } & \text { 2) Hs: dillatione. }\end{array}$ 